\title{
REVIEW
}

\section{Diseases of Echinodermata. III. Agents metazoans (Annelida to Pisces)}

\author{
Michel Jangoux
}

Laboratoire de Biologie marine (CP 160), Université Libre de Bruxelles, Ave F. D. Roosevell 50, B-1050 Bruxelles, Belgium

\begin{abstract}
Parasitic myzostomids mostly infest crinoids but a few are known from asteroids and ophiuroids; they are either gallicole, cysticole or endoparasitic. Although many copepods have been said to be ectoparasitic on echinoderms, this has been proven for only a few species. Some copepods are known to induce gall formation in the spines of echinoids or in the body wall of ophiuroids; others have been found to infest either the bursae or gonads of ophiuroids. Ascothoracid cirripeds were reported either as ectoparasites on crinoids and ophiuroids or as endoparasites in the body cavity of asteroids and spatangoid echinoids. Echinoderm castration by copepods and ascothoracids was reported several times in the literature. Parasitic crabs mostly occur on or in echinoids. Ectoparasitic crabs often exert major effects and may kill their host; gut-inhabiting species may produce conspicuous host deformation. Some species of carapid fishes are known to live either temporarily or permanently in the body cavity of holothuroids and asteroids. Carapid infestations do not seem to seriously affect the echinoderms except for species permanently inhabiting the host's coelom. Parasitic associations between echinoderms and polychaetes, tardigrads, barnacles, amphipods, tanaidaceans, acarians, pycnogonids and insects have been casually reported in the literature.
\end{abstract}

\section{INTRODUCTION}

The present paper is the third of a series of 4 that review the diseases of Echinodermata. It considers the disease agents belonging to the Annelida (Polychaeta and Myzostomida), Tardigrada, Crustacea (Copepoda, Cirripedia and Malacostraca), Arachnida, Pycnogonida, Insecta and Pisces. (Other metazoan agents have been considered in Part II; Jangoux 1987b). As discussed in Part I (Jangoux 1987a), I have adopted the definition of parasites proposed by Kinne (1980, p. 19) and used it in a very broad sense, considering disease agents (parasites sensu lato) to represent any kind of harmful associate which affects, if even slightly, the echinoderm's tissues or internal fluids (i.e. coelomic and hemal fluids)

\section{DISEASES CAUSED BY METAZOANS}

Agents: Annelida, Polychaeta

Symbiotic polychaetes were reviewed by Paris (1955) and Clark (1956), both authors stating that these polychaetes rarely affect echinoderms. While numer-

(c) Inter-Research/Printed in F. R. Germany ous species are known to live ectocommensally on echinoderms, only 3 cases of parasitism have been reported with polychaetes. According to Monticelli (1892) the eunicid Ophryotrocha puerilis occurs in the coelomic cavity of the holothuroid Ocnus planci from Naples (Italy). Ganapati \& Radhakrishna (1962) noted that $50 \%$ of the holothuroid Molpadia sp. investigated harbored the small hesionid Ancistrocyllis sp. either in the digestive tract or respiratory trees. The only case of unequivocal parasitism is that of the lumbrinereid Ophiuricola cynips which forms myzostomid-like galls at the base of the arms of the deep-sea ophiuroid Ophioglypha tumulosa (Ludwig 1905). According to Ludwig, the galls are rather large and partly protrude into the host's coelomic cavity.

\section{Agents: Annelida, Myzostomida}

The class Myzostomida (about 110 described species) occupies a peculiar place among echinoderm symbiotes. They are aberrant annelids with a small flattened body several $\mathrm{mm}$ in length. Their most extraordinary feature is their intimate association with echinoderms; in fact there are no known free-living 
Table 1. Parasitic myzostomids from echinoderms (compiled from the sources indicated). Myzostomid classification and species names according to Jägersten (1940). Hosts: A, asteroid; C, crinoid; O, ophiuroid. Records of conspicuous deformations caused by unidentified myzostomids were reported on several occasions (e.g. Carpenter 1889 for Acitinometra notata). Speel \& Dearborn (1983) noted that each of the 96 individuals of Promochocrinus kerguelensis they observed harbored 1 to 3 myzostomid cysts

\begin{tabular}{|c|c|c|c|c|c|}
\hline Myzostomid & Host & Location on/in host & Remarks & Geographical area & Source \\
\hline \multicolumn{6}{|l|}{ I. Proboscidea } \\
\hline Myzostomum beardi & $\begin{array}{l}\text { Perissometra flexilis } \\
\text { (C) }\end{array}$ & Galls on arms & $\begin{array}{l}\text { Only } 1 \text { worm } \\
\text { gall }^{-1}\end{array}$ & $\begin{array}{l}\text { NE Indian Ocean } \\
\text { (Arafura Sea) }\end{array}$ & Graff(1887) \\
\hline Myzostomum belli & $\begin{array}{l}\text { Endoxocrinus } \\
\text { alternicirrus }(\mathrm{C})\end{array}$ & Galls at base of arms & $\begin{array}{l}\text { Only } 1 \text { worm } \\
\text { gall }\end{array}$ & $\begin{array}{l}\text { NW Pacific } \\
\text { (S Philippines) }\end{array}$ & Wheeler (1896) \\
\hline $\begin{array}{l}\text { Myzostomum } \\
\text { cryptopodium }\end{array}$ & $\begin{array}{l}\text { Metacrinusinterruptus } \\
\text { (C) }\end{array}$ & Galls on arms & - & $\begin{array}{l}\text { Indian Ocean (Bay of } \\
\text { Bengal?) }\end{array}$ & Wheeler (1896) \\
\hline $\begin{array}{l}\text { Myzostomum } \\
\text { deformator }\end{array}$ & $\begin{array}{l}\text { Endoxocrinus } \\
\text { alternicirrus }(\mathrm{C})\end{array}$ & Galls in pinnules & $\begin{array}{l}2 \text { worms }\left(0^{3}, 9\right) \\
\text { gall }^{-1}\end{array}$ & $\begin{array}{l}\text { NWPacific (SE } \\
\text { Philippines) }\end{array}$ & Graff (1884) \\
\hline Myzostomum eremita & $\begin{array}{l}\text { Metacrinus moseleyi } \\
\text { (C) }\end{array}$ & $\begin{array}{l}\text { Galls at base of arms } \\
\text { and pinnules }\end{array}$ & $\begin{array}{l}\text { Only } 1 \text { worms } \\
\text { gall }^{-1}\end{array}$ & $\begin{array}{l}\text { NW Pacific(SE } \\
\text { Philippines) }\end{array}$ & Wheeler $(1896)$ \\
\hline $\begin{array}{l}\text { Myzostomum } \\
\text { pentacrini }\end{array}$ & $\begin{array}{l}\text { Endoxocrinus alter- } \\
\text { nicirrus (C) }\end{array}$ & $\begin{array}{l}\text { Slight galls extending } \\
\text { into } 3 \text { to } 6 \text { arm seg- } \\
\text { ments }\end{array}$ & $\begin{array}{l}1 \text { to } 3 \text { worms } \\
\text { gall }^{-1}\end{array}$ & $\begin{array}{l}\text { NW Pacific (SE } \\
\text { Philippines) }\end{array}$ & Graff (1884) \\
\hline $\begin{array}{l}\text { Myzostomum } \\
\text { tenuispinum }\end{array}$ & $\begin{array}{l}\text { Pachylometra inae- } \\
\text { qualis, Perissometra } \\
\text { flexilis, Charitometra } \\
\text { basicurva, Charito- } \\
\text { metraincisa (C) }\end{array}$ & $\begin{array}{l}\text { Conspicuous galls ex- } \\
\text { tending into } 2 \text { to } 3 \text { arms } \\
\text { segments }\end{array}$ & $\begin{array}{l}2 \text { worms }(\delta, 9) \\
\text { gall }^{-1} \text {; several } \\
\text { galls on each } \\
\text { infested host }\end{array}$ & $\begin{array}{l}\text { TropicaI W Pacific (SE } \\
\text { Philippines, Fiji Islands } \\
\text { and Kermadec Island) }\end{array}$ & Graff (1884) \\
\hline $\begin{array}{l}\text { Myzostomum } \\
\text { willemoesl }\end{array}$ & $\begin{array}{l}\text { Pachylometra inae- } \\
\text { qualis, Perissometra } \\
\text { flexilis, Charitometra } \\
\text { basicurva(C) }\end{array}$ & Galls in pinnules & $\begin{array}{l}2 \text { worms }(\dot{0}, 9) \\
\left.\text { gall }^{-1}\right)\end{array}$ & $\begin{array}{l}\text { Tropical W Pacific (Fiji } \\
\text { and Kermadec } \\
\text { Islands); NE Indian } \\
\text { Ocean (Arafura Sea) }\end{array}$ & $\begin{array}{l}\text { Graff (1884, } \\
1887)\end{array}$ \\
\hline \multicolumn{6}{|l|}{ II. Pharyngidea } \\
\hline $\begin{array}{l}\text { Asteriomyzostomum } \\
\text { asteriae }\end{array}$ & $\begin{array}{l}\text { Sclerasterias neglecta, } \\
\text { Sclerasterias richardi } \\
\text { (A) }\end{array}$ & $\begin{array}{l}\text { Hypertrophied pyloric } \\
\text { caeca (proximal part of } \\
\text { the caeca) }\end{array}$ & $\begin{array}{l}1 \text { to } 3 \text { worms } \\
\text { infested } \\
\text { asteroid }^{-1}\end{array}$ & Mediterranean sea & $\begin{array}{l}\text { Marenzeller } \\
(1895 \mathrm{a}, \mathrm{b}), \text { Stum- } \\
\text { mer-Traunfels } \\
\text { (1903) }\end{array}$ \\
\hline $\begin{array}{l}\text { Asteriomyzostomum } \\
\text { iisheri }\end{array}$ & Tosialeptoceramus (A) & $\begin{array}{l}\text { Coelomic cavity, } \\
\text { loosely attached } \\
\text { to body wall }\end{array}$ & - & $\begin{array}{l}\text { Tropical E Pacific (off } \\
\text { South California) }\end{array}$ & Wheeler (1904) \\
\hline $\begin{array}{l}\text { Cystimyzostomum } \\
\text { clarki }\end{array}$ & $\begin{array}{l}\text { Metacrinus rotundus } \\
\text { (C) }\end{array}$ & $\begin{array}{l}\text { Subcutaneous cysts on } \\
\text { underside of arms }\end{array}$ & $\begin{array}{l}1 \text { worm }^{\text {cyst }}{ }^{-1} \\
\text { up to } 7 \text { cysts } \\
\text { host }^{-1}\end{array}$ & $\begin{array}{l}\text { N. Pacific (Japan: } \\
\text { Sagami Sea) }\end{array}$ & $\begin{array}{l}\text { McClendon } \\
(1906)\end{array}$ \\
\hline $\begin{array}{l}\text { Cystimyzostomum } \\
\text { cysticolum }\end{array}$ & $\begin{array}{l}\text { Anthometra adriani, } \\
\text { Amphimetra discoidea, } \\
\text { Comactinia } \\
\text { meridionalis (C) }\end{array}$ & $\begin{array}{l}\text { Subcutaneous } \\
\text { calcified cysts on } \\
\text { upper side of arms }\end{array}$ & $\begin{array}{l}2 \text { worms }(\delta, 9) \\
\text { cyst }^{-1} \text {, no } \\
\text { more than } 1 \\
\text { cyst on } \\
\text { each host arm }\end{array}$ & $\begin{array}{l}\text { Cosmopolitan (Carib- } \\
\text { bean; Red Sea; Aru } \\
\text { Islands; Eastern coast } \\
\text { of Japan) }\end{array}$ & $\begin{array}{l}\text { Graff (1884), } \\
\text { McClendon } \\
\text { (1906), Rem- } \\
\text { scheid (1916), } \\
\text { Fishelson (1973, } \\
\text { 1974) }\end{array}$ \\
\hline $\begin{array}{l}\text { Cystimyzostomum } \\
\text { ijimai }\end{array}$ & $\begin{array}{l}\text { Tropiometra macro- } \\
\text { discus, Capillaster } \\
\text { multiradiatus(C) }\end{array}$ & $\begin{array}{l}\text { Subcutaneous cyst on } \\
\text { calyx (upper surface) }\end{array}$ & $\begin{array}{l}1 \text { to } 2 \text { worms } \\
\text { cyst }^{-1}\end{array}$ & $\begin{array}{l}\text { Indo W Pacific (Sagami } \\
\text { Sea, Japan; Red Sea) }\end{array}$ & $\begin{array}{l}\text { Hara \& Okada } \\
(1921), \text { Fishelson } \\
(1973,1974)\end{array}$ \\
\hline $\begin{array}{l}\text { Cystimyzostomum } \\
\text { inflator }\end{array}$ & $\begin{array}{l}\text { Neocomatella } \\
\text { pulchella. Adelometra } \\
\text { angus tiradia(C) }\end{array}$ & $\begin{array}{l}\text { Subcutaneous calcified } \\
\text { cysts at arm base } \\
\text { (upper surface) }\end{array}$ & $\begin{array}{l}2 \text { worms }(3,8) \\
\text { cyst }^{-1}\end{array}$ & $\begin{array}{l}\text { Circumtropical } \\
\text { (Papua }{ }_{i} \text { Barbados) }\end{array}$ & Graff $(1884)$ \\
\hline $\begin{array}{l}\text { Cystimyzostomum } \\
\text { murrayi }\end{array}$ & $\begin{array}{l}\text { Horaeometra duplex, } \\
\text { Stiremetra breviradia. } \\
\text { Adelometra angust- } \\
\text { iradia (C) }\end{array}$ & $\begin{array}{l}\text { Subcutaneous stalked } \\
\text { and calcified cysts on } \\
\text { calyx (upper surface) }\end{array}$ & $\begin{array}{l}2 \text { worms }(\delta .9) \\
\text { cyst }^{-1}\end{array}$ & $\begin{array}{l}\text { Circumtropical } \\
\text { (Papua; Kermadec } \\
\text { Islands; Barbados) }\end{array}$ & Graff (1884) \\
\hline $\begin{array}{l}\text { Cystimyzostomum } \\
\text { platypus }\end{array}$ & $\begin{array}{l}\text { Comanthina } \\
\text { schlegeli }(\mathrm{C})\end{array}$ & $\begin{array}{l}\text { Subcutaneous cyst on } \\
\text { calyx (upper surface) }\end{array}$ & 1 worm cyst $^{-1}$ & $\begin{array}{l}\text { W Pacific (Philippines: } \\
\text { off Samboangan) }\end{array}$ & Graff (1887) \\
\hline $\begin{array}{l}\text { Cystimyzostomum } \\
\text { rubustum }\end{array}$ & $\begin{array}{l}\text { Metacrinus rotundus } \\
\text { (c) }\end{array}$ & Cysts on arms & 1 wormcyst $^{-1}$ & $\begin{array}{l}\text { NW Pacific (Japan: } \\
\text { Sagami Sea) }\end{array}$ & $\begin{array}{l}\text { Hara \& Okada } \\
\text { (1921) }\end{array}$ \\
\hline $\begin{array}{l}\text { Cystimyzostomum } \\
\text { taeniatum }\end{array}$ & Zygometra mertoni (C) & $\begin{array}{l}\text { Juvenule in cysts on } \\
\text { pinnules, adults } \\
\text { free-living }\end{array}$ & 1 worm cyst $^{-1}$ & $\begin{array}{l}\text { NW Indlan Ocean (Aru } \\
\text { Islands) }\end{array}$ & $\begin{array}{l}\text { Remscheid } \\
(1916)\end{array}$ \\
\hline
\end{tabular}


Table 1 (continued)

\begin{tabular}{|c|c|c|c|c|c|}
\hline Myzostomid & Host & Location on/in host & Remarks & Geographical area & Source \\
\hline Mesomyzostoma katoi & $\begin{array}{l}\text { Comanthus japonicus } \\
\text { (C) }\end{array}$ & $\begin{array}{l}\text { Gonads (genital } \\
\text { pinnules) }\end{array}$ & - & Sea of Japan & Oxada (1933) \\
\hline $\begin{array}{l}\text { Mesomyzostoma } \\
\text { reichenspergi }\end{array}$ & $\begin{array}{l}\text { Amphimetra discoidea } \\
\text { (C) }\end{array}$ & $\begin{array}{l}\text { Coelomic cavity of } \\
\text { arms }\end{array}$ & $\begin{array}{l}\text { Only } 2 \text { indi- } \\
\text { viduals known }\end{array}$ & $\begin{array}{l}\text { NW Indian Ocean (Aru } \\
\text { Islands) }\end{array}$ & $\begin{array}{l}\text { Remscheid } \\
(1916)\end{array}$ \\
\hline $\begin{array}{l}\text { Protomyzostomum } \\
\text { astrocladi }\end{array}$ & $\begin{array}{l}\text { Astrocladus coniferus } \\
\text { (O) }\end{array}$ & Encysted in gonads & - & $\begin{array}{l}\text { NW Pacific (Sagami } \\
\text { Sea) }\end{array}$ & Fedotov $\{1925\}$ \\
\hline $\begin{array}{l}\text { Protomyzostomum } \\
\text { polynephris }\end{array}$ & $\begin{array}{l}\text { Gorgonocephalus arc- } \\
\text { ticus, Gorgonocephalus } \\
\text { eucnemis, Gorgono- } \\
\text { cephalus caput- } \\
\text { medusae (O) }\end{array}$ & Bursae and gonads & $\begin{array}{l}10 \text { to } 20 \\
\text { worms } \\
\text { host }^{-1}\end{array}$ & $\begin{array}{l}\text { North Sea (Scandina- } \\
\text { vlan coast): Barents } \\
\text { Sea }\end{array}$ & $\begin{array}{l}\text { Fedotov }(1912, \\
1914,1916) \\
\text { Barel \& } \\
\text { Kramers (1977) }\end{array}$ \\
\hline $\begin{array}{l}\text { Protomyzostomum } \\
\text { sagamiense }\end{array}$ & $\begin{array}{l}\text { Gorgonocephalus sp. } \\
\text { (O) }\end{array}$ & Bursae and gonads & - & $\begin{array}{l}\text { NW Pacific (Sagami } \\
\text { Sea! }\end{array}$ & Okada (1922) \\
\hline $\begin{array}{l}\text { Pulvinomyzostomum } \\
\text { pulvnar }\end{array}$ & $\begin{array}{l}\text { Leptometra phalan- } \\
\text { gnum, Antedon } \\
\text { bifida (C) }\end{array}$ & Digestive tract & $\begin{array}{l}\text { Infestation } \\
\text { level: } 10 \text { to } \\
20 \% \\
\text { (Jägersten) }\end{array}$ & $\begin{array}{l}\text { Mediterranean (Ban- } \\
\text { yuls; Naples); NE At- } \\
\text { lantic (Roscoff) }\end{array}$ & $\begin{array}{l}\text { Prouho (1892), } \\
\text { Wheeler (1896), } \\
\text { Jägersten } \\
\text { (1940), } \\
\text { Barel \& Kramers } \\
(1977)\end{array}$ \\
\hline
\end{tabular}

myzostomids, nor is there any species associated with other phyla. Myzostomids mostly infest crinoids, but a few are known from asteroids and ophiuroids. Myzostomids are highly differentiated, both morphologically and ecologically. Their almost obligatory association with crinoids (they even infested now extinct crinoids; e.g. Meyer \& Ausich 1983, Arendt 1985) suggests that they are an ancient group which evolved together with. crinoids. Myzostomids may be considered a unique case of 'symbiogenesis' involving a whole class of organisms (e.g. Clark 1921, Stummer-Traunfels 1926 , Prenant 1959).

About 25 species of myzostomids have been recorded as echinoderm parasites (Table 1), the remaining species being frequently referred to 'free-living'. However, these latter species are ectocommensals which generally live unattached on the echinoderm body surface. As pointed out by Stummer-Traunfels (1926), 3 types of parasitic myzostomids may be distinguished depending on whether they are gallicole, cysticole or endoparasitic. Endoparasitic species feed on the host's tissues, while cysticole and gallicole species are suspension feeders which divert the water current produced by the host's ambulacra (galls and cysts are most often located near the ambulacral grooves and always have 2 apertures allowing passage of directional watercurrents) (Prenant 1959). With rather few exceptions (e.g. Cystomyzostomum ijimai and Mesomyzostoma katoi; respectively Fishelson 1974, Okada 1933), parasitic myzostomids mostly infest bathyal echinoderms (in 200 to $1200 \mathrm{~m}$ water depth; Stummer-Traunfels 1926). This fact explains why these parasitoses have been so anecdotically documented.
Gallicole species belong to the genus Myzostomum. They dig into the dermal tissue of crinoids arms or pinnules (Fig. 1A, B) and build more or less spacious intradermal cavities, always located under skeletal ossicles. The cavities sometimes are very complicated, with internal partitions (e.g. in Myzostomum tenuispinum; Graff 1884). Myzostomid galls often harbor a pair of individuals. Gallicole species were termed 'deformative Arten' by Stummer-Traunfels (1926); they induce conspicuous deformation of the host's ossicles which considerably enlarge and adjust their shape to that of the myzostomid's shelter (Graff 1884, Wheeler 1896, Stummer-Traunfels 1926). Cysticole species belong to the genus Cystimyzostomum; they behave differently in that they build remarkable stalked or unstalked cysts which are always subcutaneous (i.e. located outside the host's skeleton) and protrude into the external medium (Fig. 1C). In many cases the cyst wall is reinforced by a pavement of minute skeletal plates (Graff 1884, Stummer-Traunfels 1926). Both gallicole and cysticole myzostomids induce major host reactions affecting the crinoid skeleton either by modifying size and shape of skeletal ossicles or by inducing the formation of additional skeletal plates. Such host reactions invite further investigations.

Among the 8 species of endoparasitic myzosotomids, 4 infest ophiuroid or crinoid gonads (respectively Protomyzostomum spp. and Mesomyzostoma katoi). Gonad-infesting myzostomids cause at least partial castration of their host. Fedotov (1916) reported that $P$. polynephris infests the gonads of its ophiuroid host by rupturing the wall of the bursae. Infestation may be very intense (up to 119 myzostomids per host) and the 

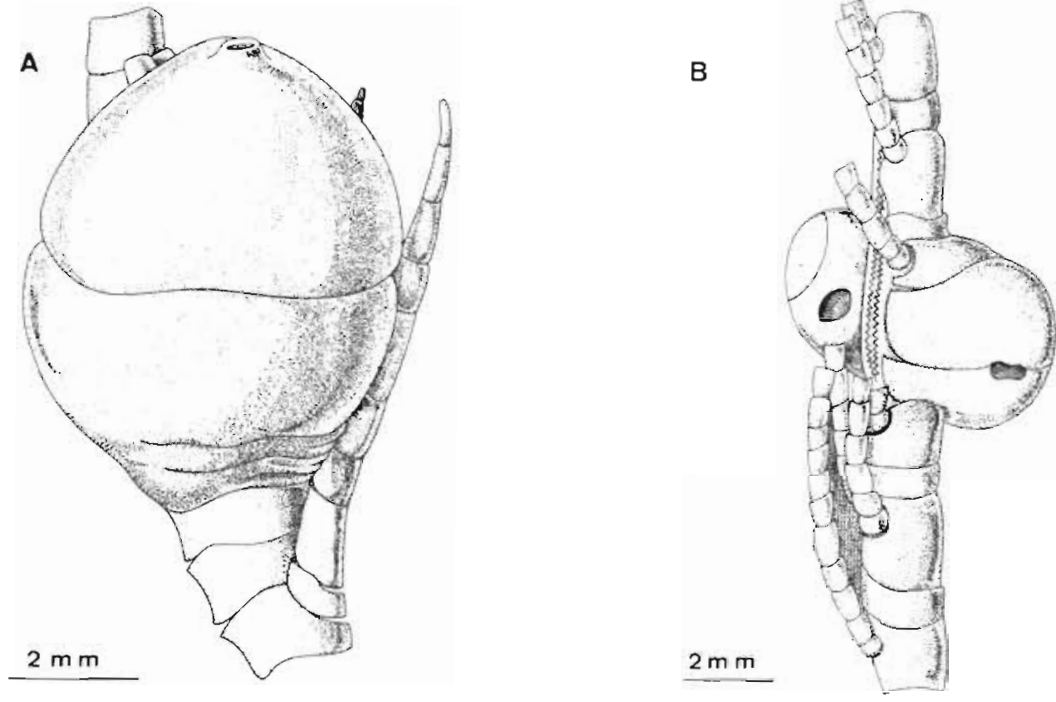

C

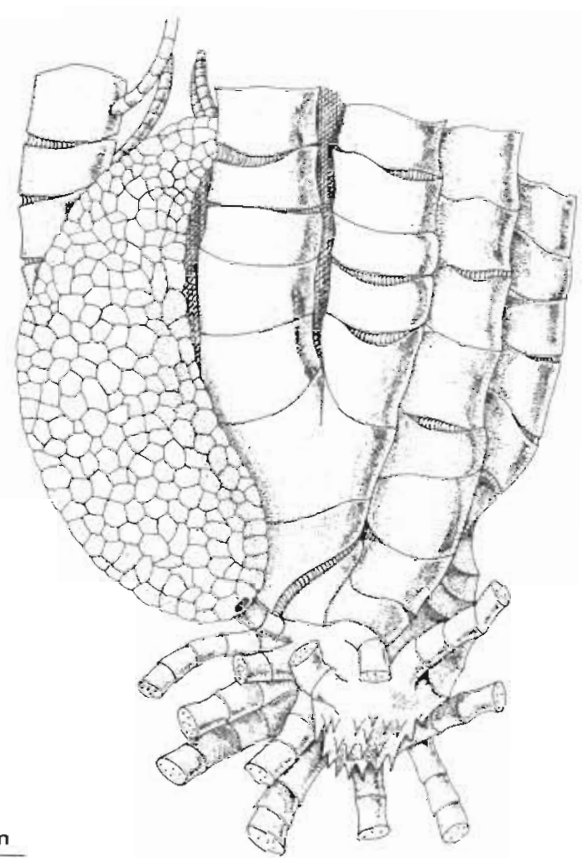

Fig. 1 Gallicole and cysticole myzostomids of crinoids. (A) Myzostomum deformator. Gall in the pinnules of Endoxocrinus alternicirrus; (B) Myzostomum tenuispinum. Gall in the arms of Pachylometra inaequalis; (C) Cystomyzostomum murrayi. Cyst on the arms of Stiremetra breviradiata. (Redrawn from Graff 1884)

parasites ingest germ cells causing direct castration of the gonads. The host reacts by progressively encysting each parasite by a thick layer of dense connective tissue in which minute calcareous ossicles are seen. Fedotov suggested moreover that germ cell dedifferentiation may also occur.

According to Remscheid (1916), Mesomyzostoma reichenspergi infests gonads, while according to Prenant (1959) it affects only the arm coelom of its crinoid host and feeds on coelomocytes. Asteriomyzostomum asteriae (Fig. 2) is said to feed on the host's digestive contents; its occurrence supposedly increases the propensity of asteroids to shed their arms (Marenzeller 1895a, b). Pulvinomyzostomum pulvinar might be more properly classified as 'semi-parasitic'. It inhabits the crinoid's digestive tract (anterior part) living intimately attached to the host's digestive epithelium without causing injury but diverting the flow of food particles entering the crinoid's mouth (Prenant 1959, West \& West 1976).

\section{Agents: Tardigrada}

The tardigrade Tetrakentron synaptae lives attached to the body surface of the synaptid a holothuroid Leptosynapta galliennei (Cuénot 1892, 1912,
Van der Land 1975, Kristensen 1980). This symbiosis has been reported only from Brittany, France (Roscoff and adjoining areas) where it is common. Very high infestation rates occur in various populations, viz. 45, 80 and even $100 \%$ (respectively Barel \& Kramers 1970, Kristensen 1980, Cuénot 1912). The number of T. synaptae per holothuroid is highly variable; it ranges from 2 to 3 up to 270 individuals (respectively Cuénot 1912, Kristensen 1980). The latter author noted that infestation occurs only from May to October leggs and juveniles are seen in June and July). Kristensen presented photographic evidence that $T$. synaptae punctures the epidermal cells of $L$. galliennei and sucks out their contents; such behavior indicates a parasitic nature of the tardigradeholothuroid association. Another tardigrade, Actinarchus doryphorus, occurs on the body surface of the small European clypeasteroid echinoid Echinocyamus pusillus. According to Schulz (1935), A. doryphorus is a facultative parasite.

\section{Agents: Crustacea, Copepoda}

There is little information regarding the relations between echinoderms and closely associated 
copepods. This is paradoxical given the high numbers of copepods recorded as echinoderm symbiotes (e.g. Humes 1980a, 1986, Stock 1968b). Table 2 lists species demonstrated or presumed to be parasites. Although many ectoparasitic copepods of echinoderms have been reported in the literature, the parasitic nature of these associations has been proven for only 4 species. viz. Cancerilla tubulata, Scottomyzon gibberum. Asterocheres Iilljeborgi, and Ophiopsyllus reductus (respectively Carton 1968, Röttger 1969, Röttger et al. 1972, Emson et al. 1985). A. lilljeborgi is not particularly adaptated to parasitic life. It is a motile copepod which uses its siphon-shaped mouth to feed on the skin of the asteroid Henricia sanguinolenta. S. gibberum mainly lives on or near the pedicellarial rosettes of Asterias rubens where it seems to feed more deeply in the host tissues (Fig. 3). O. reductus lives firmly attached to its ophiuroid host and feeds on surface tissues. As for endoparasitic species, Pyefinch (1940) concluded that Ophioica asymmetrica found in the genital bursae of ophiuroids does not feed on the host's tissues, and Changeux (1961) reported - based on casual observations - that the intracoelomic species Allantogynus delamarei 'browses' on the holothuroid's mesothelium.

Host reactions against several species of parasitic copepods have been documented. Parasitism by Scottomyzon gibberum induces the infested asteroid to produce dermal outgrowths which progressively embed the copepods (Röttger 1969). Ophiuroid hosts tend to produce a fibrous, sometimes calcified cyst around symbiotes which live in their bursae (Pyefinch 1940, Heegard 1951). However, encystment does not occur with all bursal-infesting species (Stephensen 1935a). Mortensen (1933) recorded unidentified copepods inducing gall formation in the dorsal wall of both Ophiomitrella corynephora and O. hamata. Paterson (1958) reported that cysts, presumably produced by the host, form around the intracoelomic copepod Cucumaricola notabilis. According to him, small spherical or oval cysts contain juvenile parasites. These cysts are attached to the coelomic wall either near the circumpharyngeal calcareous ring or on the cloaca near the insertion of the respiratory trees; large amorphous cysts containing mature copepods lie detached in the coelomic cavity. Jungersen (1914) reported that the ophiuroid Asteronyx loveni produces cysts around intracoelomic copepods. These cysts are attached on the ophiuroid's coelomic wall. Other intracoelomic copepods have been noted to live often 'free in the coelomic cavity' without seemingly inducing any host reaction (e.g. intracoelomic copepods of holothuroids). However, some bursal- or coelom-infesting copepods may produce conspicuous swellings of the body wall of ophiuroids. These swellings follow the outline of the parasite and do not result from a particular host reaction (Mortensen \& Stephensen 1918, Stephensen 1933, Goudey-Perrière 1979).

Copepods have been found to induce gall formation in the spines of echinothurid echinoids by Hansen (1902), Stephensen (1935b) and Stock (1968a). According to Stock, the galls consist of loose calcareous material and always occur in the middle part of the spines. Galls contain a pigmented ampula in which lives a single copepod. Another gallicole copepod, Pionodesmotes phormosomae, occurs inside the echinoid Hygrosoma petersi (Bonnier 1898, Koehler 1898, see also Mortensen 1935) (Fig. 4). P. phormosomae lives in conspicuous inner galls located in the oral part of the host's coelomic cavity. The spherical, calcified galls correspond morphologically to intracoelomic outgrowths of the echinoid body wall. Each gall opens on the host's outer body surface by a slit measuring 1 to $2 \mathrm{~mm}$ in length. The slit is protected by the spines of the echinoid. At least 1 large female copepod was found in each gall. According to Bonnier (1898) the copepod does not prey on host tissues and obtains its food mostly from the outside through the slit in the gall. Mortensen (1935) reported that empty galls progressively disappear: the slit enlarges, then the gall wall normalizes, and finally new outer appendages develop.

The way in which intracoelomic copepods infest their host has been considered only for holothuroids and asteroids. According to Paterson (1958) and Changeux (1961), holothuroids are infested by larval copepods which cross the digestive wall either at the level of the esophagus or at the level of the cloaca and respiratory trees. In asteroids, Carton (1974) showed that male Botulosoma endoarhenum penetrate the coelom of Echinaster purpureus through the respiratory papulae. Female B. endoarrhenum actually settle and grow in papulae, living in a kind of integumental cavity.

The effects of parasitic copepods on the biology of echinoderms have been considered practically only for Amphiurophilus amphiurae which parasitizes the genital bursae of a brooding ophiuroid Amphipholis squamata (e.g Goudey-Perrière 1979, 1980). The author reported that the occurrence of the parasite does not affect the host's gonads but decreases the host's fecundity by inhibiting the development of embryos incubated in the ophiuroid genital bursae. Such inhibition could result from competition for food between parasite and embryos. Gonad destruction occurred, however, in the ophiuroids Ophiomitrella clavigera and O. corynephora parasitized by an unidentified copepod (Mortensen 1933). According to Emson et al. (1985), parasitic copepods on the ophiuroid Ophiocomella ophiactoides may decrease the tendency of the host to undergo fission (cross-disc division). 


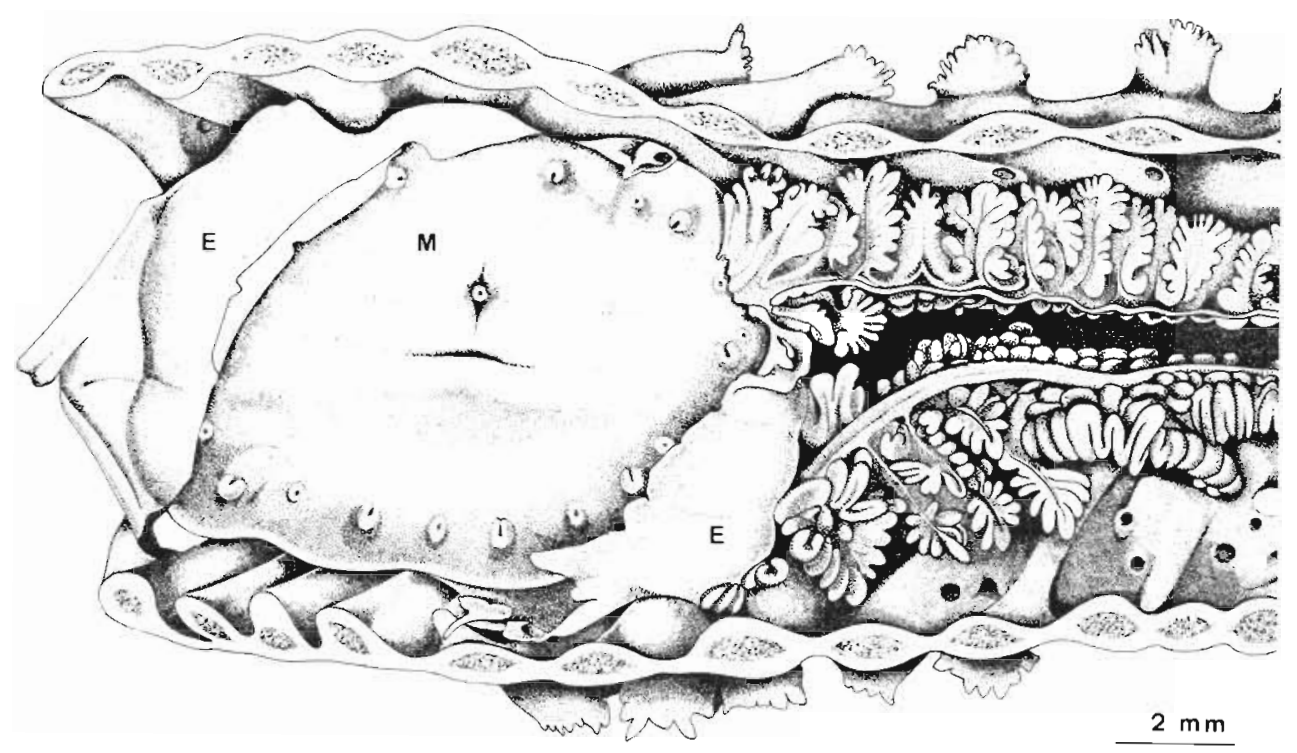

Fig. 2. Asteriomyzostomum asteriae, a myzostomid para. site of the pyloric caeca of the asteroid Sclerasterias neglec. ta. E: enlarged and deformed part of pyloric caeca harboring the parasite; $M$ : myzostomid. (Redrawn from Stummer-Traunfels 1903; slightly modified)

\section{Agents: Crustacea, Cirripedia}

Thoracid cirripeds (i.e. barnacles) sometimes attach to the outer body surface of some species of regular echinolds (Lytechninus anamesus, Tetrapygus niger, Stomopneustes variolans, Strongylocentrotus spp.) and clypeasteroids (Dendraster excentricus, Rotula orbiculus). Either of 2 situations may occur: (1) the barnacle attaches only loosely to the host's body wall overlaping an intact cutaneous epithelıum (Moore \& McPherson 1963); (2) the barnacle is strongly attached to the echninoid test, the epidermis being destroyed (Giltay 1934, Dartevelle 1940, Boolootian 1958, 1964, Strachan 1970, Ganapatı \& Sastry 1972, Hurley 1973, Bay-Schmith \& Jana 1977). Barnacles Balanus spp. have been noticed on echinoderms mainly by casual observations, except for the association between $D$. excentricus and Balanus concavus pacificus detalled by Boolootian (1964). There appears to be general agreement that the activity of pedicellariae and spines would avoid settlement of barnacle cyprids on the echinord body wall (e.g Campbell \& Rambow 1977) However, the reviewer believes that the fallure of cyprids to settle results basically from the occurrence of a cutaneous epithelium which prevents larval fixation. Presumably cyprid settlement can occur only when the echinoderm body wall is wounded. or when the epiderm is eroded for some mechanical or pathological reasons (such as bald-sea-urchin disease; Jangoux 1987a). Barnacles of the genera Pachylasma, Scalpellum and Verruca have been noticed firmly attached to the stem or cirrs of several species of stalked crinords (Clark 1921).

Ascothoracida are 'naked barnacles' that parasitize octorallian corals and echinoderms, except holothurolds. They have been found either as ectoparasites on crinolds and ophiuroids (genera Ascothorax, Parascothorax, Waginella) or as endoparasites in the coelomic cavity of asteroids and spatangoid echinoids (genera Ctenosculum, Dendrogaster, Ulophysema) (Table 3). Wagunella metacrinicola lives attached to the crnoid calyx where it forms a conspicuous depression. It feeds on the 'fluids' of the host by piercing the body wall with its oral appendages (Okada 1926). Ophiuroid-assocrated ascothoracids infest the genital bursae producing marked swellings of part of the host disc (Fig. 5). According to Wagin (1946) Ascothorax ophioctenis feeds on the cells of the bursal wall and probably also on the coelomic fluid of the host. As for intracoelomic ascothoracids, Brattström (1947) concluded that Ulophysema oeresundense directly absorbs nutrients from the echinoid's coelomic fluid, while Wagin (1976) believed that coelomocytes form the bulk of the diet of Dendrogaster spp. (Fig, 6).

Echnnoderms react against intracoelomic ascothoracids by forming a host envelope that surrounds the mantle of the parasite. According to Wagin (1946), this envelope consists of coelomocytes and covers even the mantle opening which consequently is continually cleaned and smoothed by the ascothoracid's anterior appendages; Wagin claimed that such appendage activity actually corresponds to the normal way of obtaining food by intracoelomic Dendrogaster species. However, investigations by Bresciani \& Jespersen (1985) on Ulophysema oeresundense, parasitic in the coelom of Echinocardium cordatum, showed that the envelope is made of choanocyte-like cells and that consequently it should originate from host mesothelium. A conspicuous host reaction also occurs in Parascothorax sinagodoides which lives attached in the bursal cavity near the bursal slit of 
Table 2. Parasitic copepods from echinoderms (compiled from the sources indicated). Hosts: A, asteroid; C, crinoid; E, echinoid; H, holothuroid; $\mathrm{O}$, ophiuroid

\begin{tabular}{|c|c|c|c|c|c|}
\hline Copepod & Host & Location in host & Remarks & Geographical area. & Source \\
\hline \multicolumn{6}{|l|}{ I. Harpacticoida } \\
\hline $\begin{array}{l}\text { Metis } \\
\text { holothuriae }\end{array}$ & $\begin{array}{l}\text { Actinopyga agassizı } \\
(\mathrm{H})\end{array}$ & Coelomic cavity & - & $\begin{array}{l}\text { Tropical Atlantic } \\
\text { (Bahamas) }\end{array}$ & $\begin{array}{l}\text { Edwards }(1891), \\
\text { Humes }(1980 a)\end{array}$ \\
\hline Tisbe furcata & Ocnus planci $(\mathrm{H})$ & Coelomic cavity & $\begin{array}{l}\text { Almost } 100 \% \text { of } \\
\text { holothuroids investi- } \\
\text { gated were infested } \\
\text { (Monticelli) }\end{array}$ & $\begin{array}{l}\text { Mediterranean Sea } \\
\text { (Naples) }\end{array}$ & $\begin{array}{l}\text { Monticelli } \\
\text { (1892); Humes } \\
(1980 \text { a) }\end{array}$ \\
\hline $\begin{array}{l}\text { Tisbe } \\
\text { holothuriae }\end{array}$ & Holothuria stellati $(\mathrm{H})$ & $\begin{array}{l}\text { Digestive tract (an- } \\
\text { terior part) }\end{array}$ & - & $\begin{array}{l}\text { Mediterranean Sea } \\
\text { (Banyuls) }\end{array}$ & Humes (1957) \\
\hline \multicolumn{6}{|l|}{ II. Cyclopodia } \\
\hline $\begin{array}{l}\text { Allantogynus } \\
\text { delamarei }\end{array}$ & $\begin{array}{l}\text { Holothuria tubulosa, } \\
\text { Holothuria poli, } \\
\text { Holothuria stellati }(\mathrm{H})\end{array}$ & $\begin{array}{l}\text { Anterior part of } \\
\text { coelomic cavity fixed } \\
\text { on mesothelium loccur } \\
\text { also in wall of pharynx, } \\
\text { gonads, tentacular } \\
\text { ampullae, or } \\
\text { Polian vesicles) }\end{array}$ & $\begin{array}{l}\text { H. tubulosa and } H \text {. } \\
\text { stellati: about } 2 \\
\text { copepods } \\
\text { holothuroid }{ }^{-1} \text { ( } 82 \mathrm{in-} \\
\text { fested } 117 \text { investi- } \\
\text { gated); } H \text {. poli is only } \\
\text { occasional host }\end{array}$ & $\begin{array}{l}\text { Mediterranean Sea } \\
\text { (Banyuls, Villefranche) }\end{array}$ & $\begin{array}{l}\text { Changeux } \\
(1958,1961), \\
\text { Stock \& Kleeton } \\
\text { (1963, Humes } \\
\text { (1980a) }\end{array}$ \\
\hline $\begin{array}{l}\text { Amphiurophilus } \\
\text { amphiurae }\end{array}$ & $\begin{array}{l}\text { Amphipholis squamata } \\
\text { (O) }\end{array}$ & Bursae & $\begin{array}{l}\text { About } 12 \% \text { infested } \\
\text { ophiuroids in Roscoff } \\
\text { (Goudey-Perrière) }\end{array}$ & $\begin{array}{l}\text { NE Atlantic (Roscoff); } \\
\text { North Sea (Bergen); } \\
\text { NW Atlantic (Woods } \\
\text { Hole region) }\end{array}$ & $\begin{array}{l}\text { Fewkes (1887, } \\
\text { 1888), Hérouard } \\
\text { (1906), Bocquet } \\
\text { (1952), Masson } \\
\text { (1965), Goudey- } \\
\text { Perrière (1979, } \\
\text { 1980) }\end{array}$ \\
\hline $\begin{array}{l}\text { Asterocheres } \\
\text { lilljeborgi }\end{array}$ & $\begin{array}{l}\text { Henricia sanguinolen- } \\
\text { ta (A) }\end{array}$ & $\begin{array}{l}\text { Free on outer body } \\
\text { surface }\end{array}$ & $\begin{array}{l}\text { Up to } 24 \text { copepods } \\
\text { asteroid }^{-1}\end{array}$ & $\begin{array}{l}\text { NE Atlantic (Swedish } \\
\text { coast: Gullmarfjord) }\end{array}$ & $\begin{array}{l}\text { Róttger et al. } \\
(1972), \text { Brun } \\
(1976)\end{array}$ \\
\hline $\begin{array}{l}\text { Botulosoma } \\
\text { endoarrhenum }\end{array}$ & $\begin{array}{l}\text { Echinaster purpureus } \\
\text { (A) }\end{array}$ & $\begin{array}{l}\text { Respiratory papulae (? } \\
\text { copepod); coelomic } \\
\text { cavity ( } \delta \text { copepod) }\end{array}$ & $\begin{array}{l}\text { Several dozen } \\
\text { copepods asteroid }\end{array}$ & $\begin{array}{l}\text { SW Indian Ocean } \\
\text { (Madagascar: Tuléar) }\end{array}$ & Carton (1974) \\
\hline $\begin{array}{l}\text { Calvocheres } \\
\text { engeli }\end{array}$ & $\begin{array}{l}\text { Hygrosoma hoplacan- } \\
\text { tha }(\mathrm{E})\end{array}$ & $\begin{array}{l}\text { Galls on spine at ador- } \\
\text { al side }\end{array}$ & $\begin{array}{l}\text { Two infested } \\
\text { echinoids with } 6 \text { and } \\
3 \text { copepods, respec- } \\
\text { tively }\end{array}$ & $\begin{array}{l}\text { NE Indian Ocean (off } \\
\text { Celebes, Timor Sea) }\end{array}$ & Stock $(1968 \mathrm{a})$ \\
\hline $\begin{array}{l}\text { Calvocheres } \\
\text { globosus }\end{array}$ & $\begin{array}{l}\text { Calveriosoma gracile, } \\
\text { Sperosoma quincun- } \\
\text { ciale (E) }\end{array}$ & $\begin{array}{l}\text { Galls on secondary } \\
\text { spines or on spines of } \\
\text { adoral side }\end{array}$ & $\begin{array}{l}\text { Not more than } 1 \text { q } \\
\text { copepod gall }{ }^{-1} \text { ( } 2 \text { and } \\
5 \text { galls observed on } 2 \\
\text { infested hosts) }\end{array}$ & $\begin{array}{l}\text { N Indo-Pacific (off } \\
\text { Philippines; in Hal- } \\
\text { maheira Sea; off SE } \\
\text { Japan) }\end{array}$ & $\begin{array}{l}\text { Hansen (1902). } \\
\text { Stephensen } \\
(1935 b), \text { Stock } \\
(1968 a)\end{array}$ \\
\hline $\begin{array}{l}\text { Calvocheres } \\
\text { oblongus }\end{array}$ & Hygrosoma petersl (E) & Galls on spines & - & N Pacific (SE of Japan) & $\begin{array}{l}\text { Stephensen } \\
\text { (1935b) }\end{array}$ \\
\hline $\begin{array}{l}\text { Calypsarion } \\
\text { carinatum }\end{array}$ & $\begin{array}{l}\text { Stichopus mono- } \\
\text { tuberculatus }(\mathrm{H})\end{array}$ & Internal & $\begin{array}{l}1 \text { is copepod ejected } \\
\text { from host upon } \\
\text { collection }\end{array}$ & $\begin{array}{l}\text { NW Indian Ocean } \\
\text { (Ethiopia: Dahlak } \\
\text { Archipelago) }\end{array}$ & $\begin{array}{l}\text { Stock (1968b). } \\
\text { Humes (1980a) }\end{array}$ \\
\hline $\begin{array}{l}\text { Calypsarion } \\
\text { leprum }\end{array}$ & $\begin{array}{l}\text { Actinopyga } \\
\text { mauritania, Actinopy- } \\
\text { ga miliaris, Actinopyga } \\
\text { lecanora }(\mathrm{H})\end{array}$ & Internal & $\begin{array}{l}\text { A. miliaris is most } \\
\text { common host ( } 76 \\
\text { copepods }-438 \text { and } \\
33 \&-\text { collected from } \\
726 \text { hosts) }\end{array}$ & $\begin{array}{l}\text { SW Indian Ocean } \\
\text { (Madagascar: Nossy- } \\
\text { Bé) }\end{array}$ & $\begin{array}{l}\text { Humes \& Ho } \\
\text { (1969), Humes } \\
\text { (1980a) }\end{array}$ \\
\hline $\begin{array}{l}\text { Calypsarion } \\
\text { sentosum }\end{array}$ & $\begin{array}{l}\text { Bohadschia marmorata } \\
\text { (H) }\end{array}$ & Internal & $\begin{array}{l}8 \text { copepods }(5: 39) \\
\text { collected from } 8 \text { hosts }\end{array}$ & $\begin{array}{l}\text { SW Indian Ocean } \\
\text { (Madagascar: Nossy- } \\
\text { Bé) }\end{array}$ & $\begin{array}{l}\text { Humes \& Ho } \\
(1969), \text { Humes } \\
(1980 a)\end{array}$ \\
\hline $\begin{array}{l}\text { Calypsina } \\
\text { changeuxi }\end{array}$ & $\begin{array}{l}\text { Holothuria tubulosa, } \\
\text { Holothuria stellati }(\mathrm{H})\end{array}$ & $\begin{array}{l}\text { Esophagus and } \\
\text { gonoduct }\end{array}$ & - & $\begin{array}{l}\text { Mediterranean } \\
\text { (Banyuls) }\end{array}$ & $\begin{array}{l}\text { Changeux } \\
\text { (1961), Stock \& } \\
\text { Kleeton (1963) } \\
\text { Humes (1980a) }\end{array}$ \\
\hline $\begin{array}{l}\text { Cancerilla } \\
\text { tubulata }\end{array}$ & $\begin{array}{l}\text { Amphipholis squamata } \\
\text { (O) }\end{array}$ & $\begin{array}{l}\text { Attached to outer body } \\
\text { surface }\end{array}$ & $\begin{array}{l}\text { Infestation rate ca } \\
10 \% \text { (Giard) }\end{array}$ & $\begin{array}{l}\text { NE Atlantic (Brittany; } \\
\text { North Sea) }\end{array}$ & $\begin{array}{l}\text { Giard (1887) } \\
\text { Carton (1968) }\end{array}$ \\
\hline
\end{tabular}


Table 2 (continued)

\begin{tabular}{|c|c|c|c|c|c|}
\hline Copepod & Host & Location in host & Remarks & Geographical area & Source \\
\hline $\begin{array}{l}\text { Chauliolobion } \\
\text { bulbosum }\end{array}$ & $\begin{array}{l}\text { Actinopyga echinites, } \\
\text { Actinopyga obesa }(\mathrm{H})\end{array}$ & Internal & $\begin{array}{l}\text { A. echinites: } 11 \\
\text { copepods }(4 \text { Q }, 70) \\
\text { from } 72 \text { hosts; } A \text {. ob- } \\
\text { esa: } 21 \text { copepods } \\
(49,17 \text { ) from } 1 \\
\text { host }\end{array}$ & $\begin{array}{l}\text { Tropical W Pacific } \\
\text { (New Caledonia: } \\
\text { Nouméa) }\end{array}$ & $\begin{array}{l}\text { Humes (1975, } \\
1980 \mathrm{a} \text { ) }\end{array}$ \\
\hline $\begin{array}{l}\text { Chauliolobion } \\
\text { foliaceum }\end{array}$ & Holothuria atra $(\mathrm{H})$ & Coelomic cavity & $\begin{array}{l}11 \text { copepods } \\
(50,6 \%) \text { collected }\end{array}$ & $\begin{array}{l}N \text { Indian Ocean (Gulf } \\
\text { of Mannar) }\end{array}$ & $\begin{array}{l}\text { Ummerkutty } \\
(1970)\end{array}$ \\
\hline $\begin{array}{l}\text { Clavisodalis } \\
\text { dilatatus }\end{array}$ & Diadema setosum $(\mathrm{E})$ & Esophagus & $\begin{array}{l}43 \text { copepods col- } \\
\text { lected from } 65 \\
\text { echinoids }\end{array}$ & New Caledonia & $\begin{array}{l}\text { Dojiri \& Humes } \\
\text { (1982) }\end{array}$ \\
\hline $\begin{array}{l}\text { Clavisodalis } \\
\text { salmacidis }\end{array}$ & Salmacis belli $(E)$ & Mouth and esophagus & 4 copepods & $\begin{array}{l}\text { Moreton Bay } \\
\text { (Queensland) }\end{array}$ & $\begin{array}{l}\text { Humes }(1980 b) \\
\text { Dojiri \& Humes } \\
(1.982)\end{array}$ \\
\hline $\begin{array}{l}\text { Clavisodalis } \\
\text { sentifer }\end{array}$ & Diadema setosum (E) & Esophagus & $\begin{array}{l}4 \text { copepods col- } \\
\text { lected from } 17 \\
\text { echinoids }\end{array}$ & $\begin{array}{l}\text { Moreton Bay } \\
\text { (Queensland), Ambon }\end{array}$ & $\begin{array}{l}\text { Dojiri \& Humes } \\
\text { (1982) }\end{array}$ \\
\hline $\begin{array}{l}\text { Collocheres } \\
\text { elegans }\end{array}$ & Ophiocomina nigra (O) & Attached to arm base & $\begin{array}{l}\text { Up to } 5 \text { copepods per } \\
\text { ophiuroid (infesta- } \\
\text { tion increases with } \\
\text { host size) }\end{array}$ & $\begin{array}{l}\text { Firth of Clyde (Scot- } \\
\text { land) }\end{array}$ & Gorzula $(1978)$ \\
\hline $\begin{array}{l}\text { Collocherides } \\
\text { astroboae }\end{array}$ & $\begin{array}{l}\text { Astroboa nuda, As- } \\
\text { troboa albatrossl (O) }\end{array}$ & Stomach & $\begin{array}{l}\text { A. nuda: } 2 \text { infested } \\
\text { individuals with re- } \\
\text { spectively } 29(239 \text {, } \\
6 \text { o) and more than } \\
100 \text { copepods; } \text { A. al- } \\
\text { batrossi: } 1 \text { infested } \\
\text { individual with } 25 \\
\text { copepods ( } 169,6 \text { ) }\end{array}$ & $\begin{array}{l}\text { Red Sia (Eilat; Dahlate } \\
\text { Archipelago); SE In- } \\
\text { dian Ocean (Java Sea) }\end{array}$ & Stock (1971) \\
\hline $\begin{array}{l}\text { Cucumariocola } \\
\text { notabilis }\end{array}$ & $\begin{array}{l}\text { Cucumaria frauenfeldi } \\
\text { (H) }\end{array}$ & $\begin{array}{l}\text { Coelomic cavity (free } \\
\text { crsts lying in the } \\
\text { (avity) }\end{array}$ & $\begin{array}{l}\text { Of } 337 \text { investigated } \\
\text { holothuroids, } 63 \\
\text { were infested by } 1 \text { to } \\
4 \text { cysts }\end{array}$ & $\begin{array}{l}\text { SW Indian Ocean } \\
\text { (Cape Tow Province) }\end{array}$ & Paterson (1958) \\
\hline $\begin{array}{l}\text { Dichelina } \\
\text { phormosomae }\end{array}$ & $\begin{array}{l}\text { Phormosoma bur- } \\
\text { sarium, Phormosoma } \\
\text { verticillatum, Para- } \\
\text { phor- } \\
\text { mosoma alternans }(\mathrm{E})\end{array}$ & Digestive tract & $\begin{array}{l}2 \text { copepods }(10,19) \\
\text { taken from } 1 \text { indi- } \\
\text { vidual of each host } \\
\text { species }\end{array}$ & $\begin{array}{l}\text { NW Pacific (Philip- } \\
\text { pines: off Mindanao) }\end{array}$ & $\begin{array}{l}\text { Stephensen } \\
(1933,1935 b)\end{array}$ \\
\hline $\begin{array}{l}\text { Dichelsna } \\
\text { seticauda }\end{array}$ & $\begin{array}{l}\text { Hygrosoma hoplacant- } \\
\text { ha (E) }\end{array}$ & Internal & $\begin{array}{l}59 \text { copepods taken } \\
\text { from } 1 \text { echinoid }\end{array}$ & $\begin{array}{l}\text { NE Indian Ocean } \\
\text { (Celebes: off Menado) }\end{array}$ & Stock $(1968 \mathrm{c})$ \\
\hline $\begin{array}{l}\text { Diogenella } \\
\text { deichmannae }\end{array}$ & $\begin{array}{l}\text { Holothuria arenicola } \\
\text { (H) }\end{array}$ & Internal & $\begin{array}{l}43 \text { copepods }(48 \\
39 \text { \%) collected from } \\
88 \text { individuals }\end{array}$ & $\begin{array}{l}\text { Tropical Atlantic } \\
\text { (Barbados) }\end{array}$ & $\begin{array}{l}\text { Humes \& Ho } \\
\text { (1970), Humes } \\
\text { (1980a) }\end{array}$ \\
\hline $\begin{array}{l}\text { Diogenella } \\
\text { seticauda }\end{array}$ & $\begin{array}{l}\text { Holothuria surinamen- } \\
\text { sis, Holothuria impa- } \\
\text { tiens, Holothuria } \\
\text { arenicola }(\mathrm{H})\end{array}$ & Internal & $\begin{array}{l}23 \text { copepods from } 2 \\
\text { holothuroids (Stock } \\
1968) ; 5 \text { copepods } \\
(1 \delta, 4 \text { ) from } 47 \\
\text { holothuroids }\end{array}$ & $\begin{array}{l}\text { Tropical Atlantic } \\
\text { (Puerto Rico) }\end{array}$ & $\begin{array}{l}\text { Stock }(1968 \mathrm{~b}) \\
\text { Humes } \& \text { Ho } \\
(1970), \text { Humes } \\
(1980 \mathrm{a})\end{array}$ \\
\hline
\end{tabular}


Table 2 (continued)

\begin{tabular}{|c|c|c|c|c|c|}
\hline Copepod & Host & Location in host & Remarks & Geographical area & Source \\
\hline $\begin{array}{l}\text { Diogenella } \\
\text { spinicauda }\end{array}$ & $\begin{array}{l}\text { Holothuria mexicana, } \\
\text { Actinopyga agassizi }(\mathrm{H})\end{array}$ & $\begin{array}{l}\text { Internal (ejected from } \\
\text { H. mexicana; Stock) }\end{array}$ & $\begin{array}{l}2 \text { copepods (1 } \delta .19 \text { ) } \\
\text { from H. mexicana } \\
\text { (Stock); } 46 \text { copepods } \\
(22 \delta, 249 \text { ) from } 119 \\
\text { H. mexicana, } 50 \\
\text { copepods ( } 32 \delta . \\
18 \text { \%) from } 62 \mathrm{~A} \text {. } \\
\text { agassizi (Humes \& } \\
\text { Ho) }\end{array}$ & $\begin{array}{l}\text { Tropical Atlantıc } \\
\text { (Curaçao, Bahamas, } \\
\text { Jamaica, Puerto Rıcol }\end{array}$ & $\begin{array}{l}\text { Stock }(1968 \mathrm{~b}) \\
\text { Humes \& Ho } \\
(1970), \text { Humes } \\
(1980 \mathrm{a})\end{array}$ \\
\hline $\begin{array}{l}\text { Diogenidium } \\
\text { deforme }\end{array}$ & $\begin{array}{l}\text { Holothuria glaberrima, } \\
\text { Holothuria arenicola, } \\
\text { Holothuria mexicana } \\
\text { (H) }\end{array}$ & $\begin{array}{l}\text { Internal (ejected from } \\
\text { H. glaberrima; Stock) }\end{array}$ & $\begin{array}{l}2 \text { copepods }(1 \delta, 19) \\
\text { from } 1 \mathrm{H} \text { glabernma } \\
\text { (Stock); } 7 \text { copepods } \\
(1 \delta, 6 \text { from } 87 \mathrm{H} \text {. } \\
\text { arenicola, and } 5 \\
\text { copepods }(2 \delta, 39) \\
\text { from } 24 \mathrm{H} \text { mexicana }\end{array}$ & $\begin{array}{l}\text { Tropical Atlantic (Puer- } \\
\text { to Rico, Barbados, } \\
\text { Bahamas) }\end{array}$ & $\begin{array}{l}\text { Stock (1968b), } \\
\text { Humes \& Ho } \\
\text { (1971), Humes } \\
\text { (1980a) }\end{array}$ \\
\hline $\begin{array}{l}\text { Diogenudium } \\
\text { nasutum }\end{array}$ & $\begin{array}{l}\text { Actinopyga agassizi, } \\
\text { Holothuria mexicana, } \\
\text { Holothuria grisea }(\mathrm{H})\end{array}$ & Coelomic cavity & $\begin{array}{l}9 \text { copepods }(5 \delta, 49) \\
\text { from } 3 \mathrm{H} \text { mexicana } \\
\text { (Stock); } 9 \text { copepods } \\
(4 \delta, 59) \text { from } 69 \mathrm{~A} \text {. } \\
\text { agassizi, } 10 \\
\text { copepods }(4 \delta .6 \text { ) } \\
\text { from } 29 \mathrm{H} \text { mexicana, } \\
\text { and } 6 \text { copepods }(4 \delta \text {, } \\
29) \text { from } 11 \mathrm{H} \text {.grisea } \\
\text { (Humes \& Ho) }\end{array}$ & $\begin{array}{l}\text { Tropical Atlantic } \\
\text { (Bahamas, Curaçao, } \\
\text { Jamaica, Puerto Rico) }\end{array}$ & $\begin{array}{l}\text { Edwards (1891), } \\
\text { Stock (1968b), } \\
\text { Humes \& Ho } \\
\text { (1971), Humes } \\
\text { (1980a) }\end{array}$ \\
\hline $\begin{array}{l}\text { Diogenidium } \\
\text { spinulosum }\end{array}$ & $\begin{array}{l}\text { Isostichopus } \\
\text { badionotus }(\mathrm{H})\end{array}$ & $\begin{array}{l}\text { Internal (ejected from } \\
\text { host; } \text { Stock) }\end{array}$ & $\begin{array}{l}1 \delta \text { copepod from } 1 \\
\text { holothuroid (Stock); } \\
4 \text { copepods }(2 \delta, 29) \\
\text { from } 17 \text { holothuroids } \\
\text { (Humes) }\end{array}$ & $\begin{array}{l}\text { Tropical Atlantic (Puer- } \\
\text { to Rico, Jamaica) }\end{array}$ & $\begin{array}{l}\text { Stock }(1968 \mathrm{~b}) \\
\text { Humes \& Ho } \\
\text { (1971), Humes } \\
\text { (1980a) }\end{array}$ \\
\hline $\begin{array}{l}\text { Diogenidium } \\
\text { tectum }\end{array}$ & Actinopyga agassizi $(\mathrm{H})$ & Internal & $\begin{array}{l}3 \text { o copepods from } 64 \\
\text { holothuroids }\end{array}$ & $\begin{array}{l}\text { Tropical Atlantic } \\
\text { (Jamaica, Bahamas) }\end{array}$ & $\begin{array}{l}\text { Humes \& Ho } \\
\text { (1971), Humes } \\
\text { (1980a) }\end{array}$ \\
\hline $\begin{array}{l}\text { Echinosocius } \\
\text { gulicolus }\end{array}$ & Diadema setosum (E) & Esophagus & $\begin{array}{l}85 \text { copepods col- } \\
\text { lected from } 65 \\
\text { echinoids }\end{array}$ & New Caledonia & $\begin{array}{l}\text { Dojıri \& Humes } \\
(1982)\end{array}$ \\
\hline $\begin{array}{l}\text { Enterognathus } \\
\text { comatulae }\end{array}$ & $\begin{array}{l}\text { Antedon mediterranea, } \\
\text { Antedon bifida(C) }\end{array}$ & $\begin{array}{l}\text { Digestive tract, rarely in } \\
\text { coelomic cavity }\end{array}$ & $\begin{array}{l}11 \text { copepods, ( } 26, \\
99 \text { ) from } 12 \mathrm{~A} \\
\text { mediterranea } \\
\text { (Changeux \& Dela- } \\
\text { mare Deboutteville) }\end{array}$ & $\begin{array}{l}\text { Mediterranean Sea } \\
\text { (Banyuls, Naples); NE } \\
\text { Atlantic (Dublin, Ply- } \\
\text { mouth) }\end{array}$ & $\begin{array}{l}\text { Giesbrecht } \\
(1900), \text { Grainger } \\
(1950) \text {, } \\
\text { Changeux \& De- } \\
\text { lamare-De- } \\
\text { boutteville } \\
\text { (1956), Stock } \\
\text { (1959) }\end{array}$ \\
\hline $\begin{array}{l}\text { Enterognathus } \\
\text { lateripes }\end{array}$ & $\begin{array}{l}\text { Decametra chadwicki, } \\
\text { Heterometra savignyi, } \\
\text { Oligometra serripinna } \\
\text { (C) }\end{array}$ & Digestive tract & $\begin{array}{l}\text { Not more than } 4 \\
\text { copepods found }\end{array}$ & Indian Ocean (Red Sea) & Stock (1966) \\
\hline $\begin{array}{l}\text { Lecanurius } \\
\text { intestinalis }\end{array}$ & $\begin{array}{l}\text { Actinopyga lecanora } \\
(\mathrm{H})\end{array}$ & Digestive tract & - & $\begin{array}{l}\text { NW Pacific, (Philippi- } \\
\text { nes: Bohol Island) }\end{array}$ & $\begin{array}{l}\text { Kossmann } \\
\text { (1877, quoted by } \\
\text { Stock 1968b) }\end{array}$ \\
\hline $\begin{array}{l}\text { Lecanurius } \\
\text { kossmannianus }\end{array}$ & $\begin{array}{l}\text { Actinopyga lecanora, } \\
\text { Actinopyga mulleri }(\mathrm{H})\end{array}$ & Internal & $\begin{array}{l}14 \text { copepods }(7 \delta \\
7 \text { 9) from } 11 \mathrm{~A} \text {. lecan- } \\
\text { ora and } 8 \text { copepods } \\
\left(4 \delta^{2}, 4 \text { I) from } 205 \mathrm{~A} \text {. }\right. \\
\text { mullen }\end{array}$ & $\begin{array}{l}\text { SW Indian Ocean } \\
\text { (Madagascar: Nossy- } \\
\text { Bé) }\end{array}$ & Humes (1968) \\
\hline $\begin{array}{l}\text { Lecanurius } \\
\text { planifrontalls }\end{array}$ & $\begin{array}{l}\text { Actinopyga echinites, } \\
\text { Actinopyga miliaris }(\mathrm{H})\end{array}$ & $\begin{array}{l}\text { Digestive tract (post- } \\
\text { erior part) }\end{array}$ & $\begin{array}{l}3 \text { copepods }(2 \delta, 19) \\
\text { from } 3 \text { A. echinites }\end{array}$ & $\begin{array}{l}\text { Tropical W Pacific } \\
\text { (New Caledonia; Great } \\
\text { Barrier Reef) }\end{array}$ & Humes (1980a) \\
\hline $\begin{array}{l}\text { Lernaeosaccus } \\
\text { ophiacanthae }\end{array}$ & $\begin{array}{l}\text { Ophiacantha disjuncta } \\
\text { (O) }\end{array}$ & $\begin{array}{l}\text { Coelomic cavity (pre- } \\
\text { sumably) }\end{array}$ & $\begin{array}{l}\text { Only } 1 \text { individual } \\
\text { found }\end{array}$ & $\begin{array}{l}\text { Antarctic seas (Palmer } \\
\text { Archipelago) }\end{array}$ & Heegard (1951) \\
\hline
\end{tabular}


Table 2 (continued)

\begin{tabular}{|c|c|c|c|c|c|}
\hline Copepod & Host & Location in host & Remarks & Geographical area & Source \\
\hline $\begin{array}{l}\text { Lichothuria } \\
\text { mandibularis }\end{array}$ & $\begin{array}{l}\text { Holothuria atra, } \\
\text { Holothuria scabra, } \\
\text { Holothuna nobilis, } \\
\text { Holothuria fuscopune- } \\
\text { tata }(\mathrm{H})\end{array}$ & $\begin{array}{l}\text { Internal (ejected from } \\
\text { host; Stock) }\end{array}$ & $\begin{array}{l}4 \text { copepods }(2 \delta, 29) \\
\text { from } 12 \text { H.atra } \\
\text { (Stock); } 188 \text { cope- } \\
\text { pods }(54 \delta, 1349 \text { ) } \\
\text { from } 470 H . \text { scabra, } 19 \\
\text { copepods }(6 \delta, 139) \\
\text { from } 24 H \text {. nobilis, } \\
139 \text { copepods }(34 \delta . \\
1059 \text { ) from } 345 H \text {. } \\
\text { atra, and } 10 \text { copepod } \\
\text { from H. fuscopunc- } \\
\text { tata (Humes \& Ho) }\end{array}$ & $\begin{array}{l}\text { WIndian Ocean (Red } \\
\text { Sea: Eilat; Madagascar } \\
\text { Nossy-Bé) }\end{array}$ & $\begin{array}{l}\text { Stock (1968b), } \\
\text { Humes \& Ho } \\
\text { (1969), Humes } \\
1980 \text { a }\end{array}$ \\
\hline $\begin{array}{l}\text { Ophioika } \\
\text { appendiculata }\end{array}$ & $\begin{array}{l}\text { Ophiomitrella calvi- } \\
\text { gera, Ophiacantha } \\
\text { bidentata(O) }\end{array}$ & $\begin{array}{l}\text { Bursae, forming swel- } \\
\text { ling of host's tissue }\end{array}$ & $\begin{array}{l}1 \text { to } 3 \text { copepods } \\
\text { host }^{-1} \text { (no more than } \\
1 \text { bursa infested } \\
\text { host }^{-1} \text { ) }\end{array}$ & $\begin{array}{l}\text { N Atlantic (S of Green- } \\
\text { land, S of Iceland, W of } \\
\text { Hebrides) }\end{array}$ & $\begin{array}{l}\text { Stephensen } \\
(1935 \mathrm{~b}, 1940)\end{array}$ \\
\hline $\begin{array}{l}\text { Ophioika } \\
\text { asymmetrica }\end{array}$ & Ophiacantha imago $(O)$ & $\begin{array}{l}\text { Bursae, forming slight } \\
\text { swelling of host disc }\end{array}$ & $\begin{array}{l}\text { Each of the } 2 \text { infested } \\
\text { ophiuroids investi- } \\
\text { gated had a pair ( } d \text {. } \\
\text { \$) of copepodsen- } \\
\text { cysted in } 1 \text { of their } \\
\text { bursae }\end{array}$ & Antarctic seas & Pyefinch (1940) \\
\hline $\begin{array}{l}\text { Ophioika } \\
\text { ophiacanthae }\end{array}$ & Ophiacantha severa $(0)$ & $\begin{array}{l}\text { Bursae, forming swel- } \\
\text { ling of host disc }\end{array}$ & $\begin{array}{l}\text { Only } 19 \text { copepod } \\
\text { found }\end{array}$ & $\begin{array}{l}\text { SE Indian Ocean (Bali } \\
\text { Sea) }\end{array}$ & $\begin{array}{l}\text { Stephensen } \\
\text { (1933) }\end{array}$ \\
\hline $\begin{array}{l}\text { Ophioika } \\
\text { tenuibrachia }\end{array}$ & $\begin{array}{l}\text { Ophiacantha vivipara, } \\
\text { Ophiacantha disjuncta } \\
\text { (O) }\end{array}$ & Bursae (presumably) & 8 copepods found & $\begin{array}{l}\text { Antarctic seas (South } \\
\text { Georgia } \text { Adelaide } \\
\text { Land) }\end{array}$ & $\begin{array}{l}\text { Heegaard } \\
\text { (1951) }\end{array}$ \\
\hline $\begin{array}{l}\text { Ophiopsyllus } \\
\text { reductus }\end{array}$ & $\begin{array}{l}\text { Ophiocomella ophiac- } \\
\text { toides (O) }\end{array}$ & $\begin{array}{l}\text { Oral and lateral parts of } \\
\text { arm base }\end{array}$ & $\begin{array}{l}40 \text { to } 65 \% \text { of host } \\
\text { population para- } \\
\text { sitized depending on } \\
\text { period of year. Usual- } \\
\text { ly } 1 \text { to } 3 \text { copepods } \\
\text { ophiuroid } \\
\text {-1 }\end{array}$ & Jamaica & $\begin{array}{l}\text { Emson etal. } \\
\text { (1985) }\end{array}$ \\
\hline $\begin{array}{l}\text { Pinnodesmotes } \\
\text { phormosomae }\end{array}$ & Hygrosoma petersi $I^{1}(\mathrm{E})$ & Intracoelomic galls & $\begin{array}{l}1 \text { or } 2(\delta, Q) \\
\text { copepods gall }\end{array}$ & NEAtlantic (Azores) & $\begin{array}{l}\text { Koehler (1898) } \\
\text { Bonnier (1898) }\end{array}$ \\
\hline $\begin{array}{l}\text { Scottomyzon } \\
\text { gibberum }\end{array}$ & Asterias rubens $(\mathrm{A})$ & $\begin{array}{l}\text { Galls in rosettes of } \\
\text { pedicellariae }\end{array}$ & 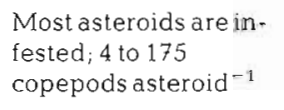 & $\begin{array}{l}\text { North Sea (off Helgo- } \\
\text { land; Kattegat) }\end{array}$ & $\begin{array}{l}\text { Röttger (1969, } \\
\text { see also Barel \& } \\
\text { Kramers }(1977)\end{array}$ \\
\hline $\begin{array}{l}\text { Synapticola } \\
\text { teres }\end{array}$ & $\begin{array}{l}\text { Polyplectana kefer- } \\
\text { steini, Synapta } \\
\text { maculata }(\mathrm{H})\end{array}$ & $\begin{array}{l}\text { Coelomic cavity, diges- } \\
\text { tive tract (posterior } \\
\text { part) }\end{array}$ & $\begin{array}{l}5 \text { copepods }(2 \delta, 39) \\
\text { free in coelomic cavi- } \\
\text { ty (Voigt) }\end{array}$ & $\begin{array}{l}\text { Indian Ocean (Amboi- } \\
\text { na): W Pacific(Queens- } \\
\text { land) }\end{array}$ & $\begin{array}{l}\text { Voigt (1892), } \\
\text { Humes (1979) }\end{array}$ \\
\hline \multicolumn{6}{|l|}{ III. Monstrilloida } \\
\hline $\begin{array}{l}\text { Thespesiop- } \\
\text { syllus paradoxus }\end{array}$ & $\begin{array}{l}\text { Ophiothrix fragilis, } \\
\text { Ophiopholisaculeata } \\
\text { (O) }\end{array}$ & Stomach folds & $\begin{array}{l}\text { About } 50 \% \text { of } O \text {. } \\
\text { aculeatainfested }\end{array}$ & $\begin{array}{l}\text { NorthSea (Gullmar- } \\
\text { fjord) }\end{array}$ & $\begin{array}{l}\text { Bresciani \& Lut- } \\
\text { zen }(1962)\end{array}$ \\
\hline $\begin{array}{l}\text { IV.Incertaesedis } \\
\text { Arthrochor- } \\
\text { deumium } \\
\text { appen- } \\
\text { diculosum }\end{array}$ & Astrocharisgracilis $(\mathrm{O})$ & Galls at arm base & $\begin{array}{l}\text { At least } 2 \text { copepods } \\
(\delta, Q) \text { found }\end{array}$ & $\begin{array}{l}\text { NW Pacific(Philippi- } \\
\text { nes: Mindanao) }\end{array}$ & $\begin{array}{l}\text { Mortensen \& } \\
\text { Stephensen } \\
\text { (1918) }\end{array}$ \\
\hline $\begin{array}{l}\text { Arthrochor- } \\
\text { deumium } \\
\text { asteromorphae }\end{array}$ & $\begin{array}{l}\text { Asteromorpha koehleri } \\
\text { (O) }\end{array}$ & Gallsatarmbase & $\begin{array}{l}\text { Only } 1 \text { copepod } \\
\text { found }\end{array}$ & $\begin{array}{l}\text { NEIndian Ocean (Am- } \\
\text { boina) }\end{array}$ & $\begin{array}{l}\text { Stephensen } \\
\text { (1933) }\end{array}$ \\
\hline $\begin{array}{l}\text { Codoba } \\
\text { discoveryi }\end{array}$ & $\begin{array}{l}\text { Ophiurameridionalis } \\
\text { (O) }\end{array}$ & $\begin{array}{l}\text { Calcified cysts inside } \\
\text { bursa }\end{array}$ & $\begin{array}{l}3 \text { infestedophiuroids } \\
\text { were found }\end{array}$ & $\begin{array}{l}\text { AntarcticSea (South } \\
\text { Georgia) }\end{array}$ & Heegard (1951) \\
\hline $\begin{array}{l}\text { Chordeumium } \\
\text { obesum }\end{array}$ & Asteronyxloveni $(\mathrm{O})$ & $\begin{array}{l}\text { Cysts within coelomic } \\
\text { cavity (attached cysts) }\end{array}$ & $\begin{array}{l}\text { Almost } 100 \% \text { infesta- } \\
\text { tion; no morethan } 1 \\
\text { copepodgall }\end{array}$ & NorthSea (Skagerrak) & $\begin{array}{l}\text { Mortensen } \\
\text { (1912), } \\
\text { Jungersen } \\
(1912,1914)\end{array}$ \\
\hline $\begin{array}{l}\text { Parachor- } \\
\text { deumium } \\
\text { tetraceros }\end{array}$ & $\begin{array}{l}\text { Amphipholissquamata } \\
\text { (O) }\end{array}$ & Coelomiccavity & $\begin{array}{l}\text { Only } 1 \text { copepodob- } \\
\text { served }\end{array}$ & $\begin{array}{l}\text { Mediterranean (Ville- } \\
\text { franche) }\end{array}$ & $\begin{array}{l}\text { Le Calvez } \\
\text { (1938), Bocquet } \\
\text { (1952) }\end{array}$ \\
\hline${ }^{1}$ Indentifted Phor & mosoma uranus by Koe & r (1898) & & & \\
\hline
\end{tabular}



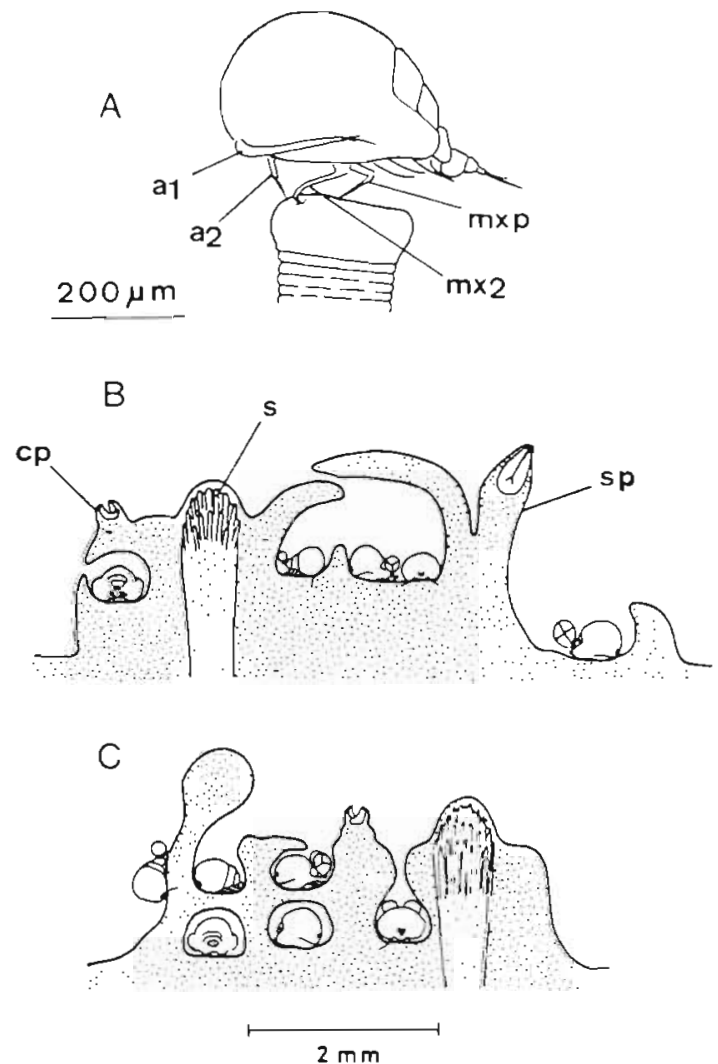

Fig. 3. Scottomyzon gibberum, an ectoparasitic copepod of the asteroid Asterias rubens. (A) Female on tube-foot tip. (B \& C) Copepods embedded in dermal tissue of a pedicellarial rosette. a1 \& a2: antennae; cp: crossed pedicellana; mxp: maxilliped; mx2: maxilla; s: spine; $\mathrm{sp}$ : straight pedicellaria (After Röttger 1969)

Ophiura quadrispina (Wagin 1964, 1976). The ophiuroid first encysts the parasite with its own tissues; then both cyst and parasite grow into the bursal cavity. The cyst is gradually ejected from the cavity through the bursal slit. $P$. sinagodoides apparently has adapted its life cycle to the reaction of its host, as rejected cysts as a rule include infesting ascothoracid larvae. According to Grygier (1985b) the asteroid-associated ascothoracid Endaster hamatosculum lives in conspicuous inner galls located in the arm coelom of its host. Galls are calcified and correspond morphologically to intracoelomic outgrowths of the asteroid body wall; each gall opens on the host's outer body surface by a slit-like hole.

Ascothoracids may castrate their host. Thus Ascothorax ophioctenis causes complete castration of Ophiocten sericerum, even though it does not feed on the host's gonads. Wagin (1946) found a single juvenile A. ophioctenis to inhibit the activity of the germinal epithelium leading to a regression of the whole gonad. Similar castration occurs in spatangoids infested with large-sized Ulophysema oeresundense. According to
Brattström (1947), castration results from competition for food between gonads and ascothoracid. Casual observations of host castration have been made also by Yosii (1928b), Fisher (1930) and Korschelt (1933). Heavy infestation of Ophionotus victoriae by Ascothorax gigas (up to 7 genital bursae infested) causes occlusion of the ophiuroid mouth opening and reduces the development of the gonads (Grygier \& Fratt 1984). The gonads do not completely regress, however. The stomach volume is reduced, but there is no demonstrable reduction in the volume of stomach contents

According to Brattström (1947) infesting larvae of Ulophysema oeresundense usually penetrate their host through the genital apertures and also through the ambulacral pores. Infesting larvae thus reach either the gonadal lumen or the axial sinus. They must cross the wall of the gonad or of the axial sinus in order to reach the general coelomic cavity where they normally grow and reproduce. When mature, Ulophysema spp. most frequently attach to the apical part of the host's body wall in which they bore holes up to $1 \mathrm{~mm}$ in diameter. These holes are used by the larvae to escape from the host. Grygier (1981) suggested that the release of larvae from a female Dendrogaster antarcticus into the asteroid coelom is produced by rupturing of the mantle of the female. Larvae of Dendrogaster tasmaniensis penetrate the asteroid Allostichaster polyplax through respiratory papulae; they infest the coelom and escape by crossing the asteroid's stomach wall and passing to the outside through its mouth (Hickman 1959).

\section{Agents: Crustacea, Malacostraca}

Associations between amphipods and echinoderms were reviewed by Vader (1978). A parasitic relation has been inferred by Shoemaker (1919) for Laphystiopsis iridometra which lives embedded in the calyx of the crinold Iridometra melpomene. Typical ectoparasitism occurs with the North Sea species Epimerja parasitica which feed on the outer tissues of the holothuroid Stichopus tremulus and the asteroid Porania pulvillus (Vader 1978). According to Ruffo (1957), the amphipods Jassia ocia and Aristias negletus occur at Banyuls (France, Mediterranean Sea) in the coelomic cavity of the holothuroid Stichopus regalis and the crinoid Antedon mediterranea, respectively.

An unexpected association between the tanaidacean Exspina typica and 3 species of deep-sea holothuroids has been reported by Thurston et al. (1987). E. typica should be considered a facultative parasite; it occurs either in the intestine or body cavity of its host.

Crabs associated with and potentially harmful to echinoderms belong to 3 distinct families: 


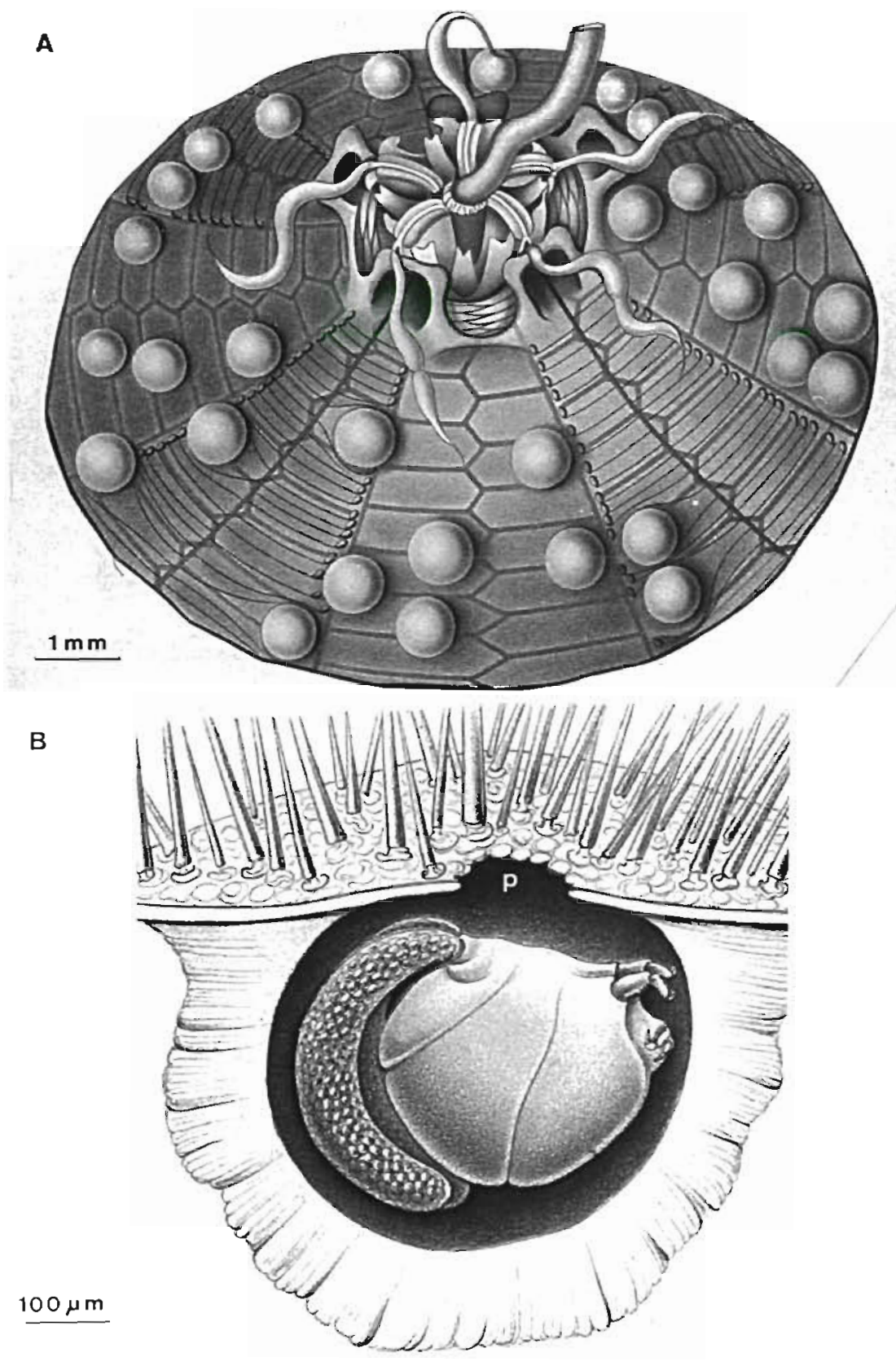

Fig. 4. Pionodesmotes phormosomae, a gallicole copepode parasite of the echinoid Hygrosoma petersi. (A) Inner view of the oral part of a dissected echinoid showing the location of calcified galls. (B) Section through gall containing an ovigerous female. p: outer pore of the gall. (A after Koehler 1898; B after Bonnier 1898)

Pinnotheridae (genera Dissodactylus, Ophisthopus, Pinnaxodes, Pinnixa, Pinnotheres), Parthenopidae (genera Echinoecus, Zebrida), and Portunidae (genus Lissocarcinus) (Table 4). Feeding habits of associated species of Ophisthopus, Pinnixa, Pinnotheres and Lissocarcinus have not been reported. Presumably these forms do not feed on host tissues, nor cause any other detrimental effects, except to slightly wound the wall of the respiratory trees or of the cloaca (Tao 1930. Jones \& Mahadevan 1965). Species inhabiting the posterior part of the echinoid digestive tract (Echinoecus convictor, E. pentagonus, E. rathbunae and Pinnaxodes chilensis) are generally said to feed on host fecal pellets (e.g. Miyake 1939, Fenucci 1967). Trophic relations between $E$. pentagonus and the echinoid Echinothrix calamaris were studied carefully by Castro (1971) (see also Suzuki \& Takeda 1974). Males and small immature females inhabit the peristomeal region where they feed on epithelial tissue and tube feet, damage being in equilibrium with the regenerating capacities of the host. Large mature females live in the rectum and ingest material from fecal pellets and aggregates of pigmented coelomocytes that migrate across the rectal wall. 
Table 3. Parasitic ascothoracid cirripeds (compiled from the sources indicated). Ascothoracid species names according to Wagin (1976) and Grygier (1981 to 1983). Hosts: A, asteroids; C, crinoids, E, echınoids; O, ophiuroids. Unidentified species of ascothoracids were reported from asteroids by Fisher (1940; Diplasterias meridionalis) and from ophiuroids by Bartsch (1982; Ophiurolepis inornatal

\begin{tabular}{|c|c|c|c|c|c|}
\hline Ascothoracid & Host & $\begin{array}{l}\text { Location } \\
\text { on/in host }\end{array}$ & Remarks & Geographical area & Source \\
\hline $\begin{array}{l}\text { Ascothorax } \\
\text { bulbosus }\end{array}$ & $\begin{array}{l}\text { Amphiura belgicae, Am- } \\
\text { phiura microplax }(0)\end{array}$ & Bursae & 1 ascothoracid host ${ }^{-1}$ & $\begin{array}{l}\text { Southern Atlantic (off } \\
\text { South Georgia) }\end{array}$ & Heegard (1951) \\
\hline $\begin{array}{l}\text { Ascothorax } \\
\text { gigas }\end{array}$ & Ophinotus victoriae (O) & Bursae & $\begin{array}{l}\text { Up to } 27 \text { parasites } \\
\text { host }^{-1} \text { (Grygier \& Fratt) }\end{array}$ & $\begin{array}{l}\text { South Sandwich Is- } \\
\text { lands }\end{array}$ & $\begin{array}{l}\text { Wagin (1968), Gry- } \\
\text { gier (1983c), Gry- } \\
\text { gier \& Fratt (1984) }\end{array}$ \\
\hline $\begin{array}{l}\text { Ascothorax } \\
\text { mortensen }\end{array}$ & Amphiusa microplax $(O)$ & Bursae & - & South Georgia & Grygier (1983c) \\
\hline $\begin{array}{l}\text { Ascothoras } \\
\text { ophioctenis }\end{array}$ & Ophiocten sericeum $(\mathrm{O})$ & Bursae & $\begin{array}{l}\text { Infestation rate: } 0.7 \text { to } \\
3.4 \% \text { (Wagin) }\end{array}$ & $\begin{array}{l}\text { Barents Sea; Kara Sea; } \\
\text { North Atlantic laround } \\
\text { Iceland and Faroe Is- } \\
\text { lands) }\end{array}$ & $\begin{array}{l}\text { Djakonov (1914), } \\
\text { Stephensen } \\
(1935 \text { a). Wagin } \\
(1946)\end{array}$ \\
\hline $\begin{array}{l}\text { Ascothorax } \\
\text { pilocaudatus }\end{array}$ & $\begin{array}{l}\text { Ophiosphalma ar- } \\
\text { migerum }(O)\end{array}$ & Bursae & - & NE Atlantic & Grygler (1983c) \\
\hline $\begin{array}{l}\text { Ctenosculum } \\
\text { hawaiiense }\end{array}$ & Brisinga evermanni (A) & Coelomic cavity & - & $\begin{array}{l}\text { Tropical W Pacific } \\
\text { (Hawaii) }\end{array}$ & $\begin{array}{l}\text { Heath }(1910), \text { Wa- } \\
\text { rén }(1981)\end{array}$ \\
\hline $\begin{array}{l}\text { Dendrogaster } \\
\text { antarcticus }\end{array}$ & $\begin{array}{l}\text { Acodontaster con- } \\
\text { spicuus (A) }\end{array}$ & Coelomin cavity & Infestation level ca $2 \%$ & $\begin{array}{l}\text { Antarctic seas (off Ross } \\
\text { Island) }\end{array}$ & $\begin{array}{l}\text { Fisher (1930), Gry- } \\
\text { gier (1981) }\end{array}$ \\
\hline $\begin{array}{l}\text { Dendrogaster } \\
\text { arborescens }\end{array}$ & $\begin{array}{l}\text { Dipsacaster sladeni, } \\
\text { Coscinasterias } \\
\text { calamaria (A) }\end{array}$ & Coelomic cavity & $\begin{array}{l}1 \text { to } 3 \text { ascothoracids } \\
\text { host }{ }^{-1} \text { (infestation not } \\
\text { uncommon) (Okada) }\end{array}$ & $\begin{array}{l}\text { Southern Indian } \\
\text { Ocean (off Cape } \\
\text { Town); Misaki (Japan) }\end{array}$ & $\begin{array}{l}\text { Le Roi }(1905,1907) \text {. } \\
\text { Okada }(1925)\end{array}$ \\
\hline $\begin{array}{l}\text { Dendrogaster } \\
\text { arbusculus }\end{array}$ & $\begin{array}{l}\text { Hippastena californica } \\
\text { (A) }\end{array}$ & Coelomic cavity & 1 observation & $\begin{array}{l}\text { NE Pacific (off } \\
\text { California) }\end{array}$ & $\begin{array}{l}\text { Fisher (1911), Gry- } \\
\text { gier (1982) }\end{array}$ \\
\hline $\begin{array}{l}\text { Dendrogaster } \\
\text { arctica }\end{array}$ & $\begin{array}{l}\text { Leptasterias groenlandi- } \\
\text { ca (A) }\end{array}$ & Coelomic cavity & - & N Pacific (Bering Sea) & $\begin{array}{l}\text { Fisher (1930), Kor- } \\
\text { schelt (1933), Wa- } \\
\text { gin (1950), Grygier } \\
(1986)\end{array}$ \\
\hline $\begin{array}{l}\text { Dendrogaster } \\
\text { argentinensis }\end{array}$ & Anasterias minuta (A) & Coelomic cavity & $\begin{array}{l}5 \text { asteroids infested } \\
\text { (326 investigated) }\end{array}$ & SW Atlantic & $\begin{array}{l}\text { Grygier \& Salvat } \\
(1984)\end{array}$ \\
\hline $\begin{array}{l}\text { Dendrogaster } \\
\text { astericola }\end{array}$ & $\begin{array}{l}\text { Henricia sanguinolenta } \\
\text { (A) }\end{array}$ & Coelomic cavity & $\begin{array}{l}3 \text { infested } H \text {. } \\
\text { sanguinolenta (500 in- } \\
\text { vestigated) }\end{array}$ & $\begin{array}{l}\text { Barents Sea (White } \\
\text { Sea) }\end{array}$ & Knipowitsch (1891) \\
\hline $\begin{array}{l}\text { Dendrogaster } \\
\text { asternae }\end{array}$ & Asterina burtonj $(A)$ & Coelomic cavity & $\begin{array}{l}1 \text { to } 10 \text { ascothoracids } \\
\text { asteroid }^{-1}\end{array}$ & $\begin{array}{l}\text { Red Sea (Gult of } \\
\text { Aqaba) }\end{array}$ & Achutuv (1971) \\
\hline $\begin{array}{l}\text { Dendrogaster } \\
\text { astropectinis }\end{array}$ & $\begin{array}{l}\text { Astropecten scoparius } \\
\text { (A) }\end{array}$ & Coelomic cavity & $\begin{array}{l}5 \text { infested asteroids } \\
\text { (250 investigated) }\end{array}$ & Misaki (Japan) & Yosii (1928b) \\
\hline $\begin{array}{l}\text { Dendrogaster } \\
\text { beringensis }\end{array}$ & $\begin{array}{l}\text { Eremicaster tenebrarius, } \\
\text { Hyphalaster inermis (A) }\end{array}$ & Coelomic cavity & - & Bering Sea & $\begin{array}{l}\text { Wagin (1957), Mad- } \\
\text { sen (1961), Grygier } \\
\text { (1985a) }\end{array}$ \\
\hline $\begin{array}{l}\text { Dendrogaster } \\
\text { dichotomus }\end{array}$ & Crossaster papposus (A) & Coelomic cavity & $\begin{array}{l}3 \text { infested asterolds (13 } \\
\text { investigated) }\end{array}$ & NE Pacific & Wagin (1950) \\
\hline $\begin{array}{l}\text { Dendorgaster } \\
\text { dogieli }\end{array}$ & Pteraster obscurus (A) & Coelomıc cavity & - & Bering Sea & Wagin (1950) \\
\hline $\begin{array}{l}\text { Dendrogaster } \\
\text { elegans }\end{array}$ & Leptasterias polaris (A) & Coelomic cavity & - & $\begin{array}{l}\text { Bering Sea; Gulf of St } \\
\text { Lawrence }\end{array}$ & $\begin{array}{l}\text { Wagin (1950), Gry- } \\
\text { gier (1986) }\end{array}$ \\
\hline $\begin{array}{l}\text { Dendorgaster } \\
\text { fisheri }\end{array}$ & $\begin{array}{l}\text { Pedicellaster magister } \\
\text { megalabis (A) }\end{array}$ & Coelomic cavity & - & $\begin{array}{l}\text { NE Pacific (off } \\
\text { California) }\end{array}$ & $\begin{array}{l}\text { Fisher (1928), Gry- } \\
\text { gier (1982) }\end{array}$ \\
\hline $\begin{array}{l}\text { Dendrogaster } \\
\text { iwanowi }\end{array}$ & Leptasterias fisheri $(\mathrm{A})$ & Coelomic cavity & - & Bering Sea & Wagin (1950) \\
\hline $\begin{array}{l}\text { Dendrogaster } \\
\text { leptasteriae }\end{array}$ & Leptasterias fisheri (A) & Coelomic cavity & - & Bering Sea & Wagin $(1950)$ \\
\hline $\begin{array}{l}\text { Dendrogaster } \\
\text { ludwigi }\end{array}$ & $\begin{array}{l}\text { Echinaster luzonicus, } \\
\text { Certonardoa semire- } \\
\text { gularis, Nepanthia bel- } \\
\text { cheri (A) }\end{array}$ & Coelomic cavity & - & $\begin{array}{l}\text { W. Pacific (Philippines, } \\
\text { Japan Sea; Tasmania) }\end{array}$ & $\begin{array}{l}\text { Le Roi }(1905,1907), \\
\text { Yosii }(1928 b) \\
\text { Kenny }(1959)\end{array}$ \\
\hline $\begin{array}{l}\text { Dendrogaster } \\
\text { murmanensis }\end{array}$ & $\begin{array}{l}\text { Crossaster papposus, } \\
\text { Solaster endeca (A) }\end{array}$ & Coelomic cavity & - & $\begin{array}{l}\text { Barents Sea; N Pacific } \\
\text { (Okhotsk Sea) }\end{array}$ & $\begin{array}{l}\text { Korschelt (1933), } \\
\text { Wagin }(1950)\end{array}$ \\
\hline $\begin{array}{l}\text { Dendrogaster } \\
\text { okadai }\end{array}$ & $\begin{array}{l}\text { Coscinasterias } \\
\text { calamaria }(\mathrm{A})\end{array}$ & Coelomic cavity & - & Misaki (Japan) & Yosii $(1928 b)$ \\
\hline
\end{tabular}


Table 3 (continued)

\begin{tabular}{|c|c|c|c|c|c|}
\hline Ascothoracid & Host & Location on/in host & Remarks & Geographical area & Source \\
\hline $\begin{array}{l}\text { Dendrogaster } \\
\text { onentalis }\end{array}$ & Leptastenas polaris (A) & Coelomic cavity & - & Bering Sea & Wagin $\{1950\}$ \\
\hline $\begin{array}{l}\text { Dendrogaster } \\
\text { punctata }\end{array}$ & Poraniopsis inflata (A) & Coelomic cavity & - & $\begin{array}{l}\text { NE Pacific (off } \\
\text { Calitornia) }\end{array}$ & Grygier(1982) \\
\hline $\begin{array}{l}\text { Dendrogaster } \\
\text { ramosus }\end{array}$ & Leptasterias fisheri (A) & Coelomic cavity & - & Bering Sea & Wagin (1950) \\
\hline $\begin{array}{l}\text { Dendrogaster } \\
\text { rimskykor- } \\
\text { sakowi }\end{array}$ & $\begin{array}{l}\text { Ctenodiscus crispatus, } \\
\text { Hippastena leiopelta } \\
\text { (A) }\end{array}$ & Coelomic cavity & - & $\begin{array}{l}\text { NW Pacific (Okhotsk } \\
\text { Sea) }\end{array}$ & Wagin (1950) \\
\hline $\begin{array}{l}\text { Dendrogaster } \\
\text { sagittana }\end{array}$ & Sidonaster vaneyi (A) & Coelomic cavity & $\begin{array}{l}2 \text { individuals in a } \\
\text { single asteroid }\end{array}$ & Philppine Seas & $\begin{array}{l}\text { Fisher (1919), } \\
\text { Grygier (1985a) }\end{array}$ \\
\hline $\begin{array}{l}\text { Dendrogaster } \\
\text { tasmaniae }\end{array}$ & $\begin{array}{l}\text { Allostichaster polyplax } \\
\text { (A) }\end{array}$ & Coelomic cavity & $\begin{array}{l}1 \text { ascothoracid as- } \\
\text { teroid }{ }^{-1} \text { ( } 26 \text { infested/ } \\
116 \text { investigated) }\end{array}$ & Around Tasmania & Hickman (1959) \\
\hline $\begin{array}{l}\text { Endaster } \\
\text { hamatosculum }\end{array}$ & Zeroaster carinatus (A) & Intracoelomic galls & $\begin{array}{l}1 \text { to } 2 \text { ascothoracids } \\
\text { asterold } \\
-1\end{array}$ & Philippines Sea & Grygier (1985b) \\
\hline $\begin{array}{l}\text { Parascothorax } \\
\text { synagodoides }\end{array}$ & $\begin{array}{l}\text { Ophiura quadrispina } \\
\text { (O) }\end{array}$ & In cysts in bursae & $\begin{array}{l}1 \text { to } 9 \text { ascothoracids } \\
\text { ophnuroid }^{-1}\end{array}$ & Okhotsk Sea & Wagin (1964) \\
\hline $\begin{array}{l}\text { Ulophysema } \\
\text { oeresundense }\end{array}$ & $\begin{array}{l}\text { Echinocardium cor- } \\
\text { datum, Echinocardium } \\
\text { flavescens, Brissopsis } \\
\text { lyrifera (E) }\end{array}$ & $\begin{array}{l}\text { Coelomic cavity; more } \\
\text { rarely gonads, am- } \\
\text { bulacral ampullae or } \\
\text { axial sinus }\end{array}$ & $\begin{array}{l}1 \text { to } 9 \text { (mostly } 1 \text { ) asco- } \\
\text { thoracids echinoid }{ }^{-1} \\
\text { (all stations together: } \\
814 \text { infested/42874 } \\
\text { investigated) (Bratt- } \\
\text { ström } 1947 \text { ); infesta- } \\
\text { tion rate: } 20 \text { to } 25 \% \\
\text { (Brescianı \& Jesper- } \\
\text { sen) }\end{array}$ & $\begin{array}{l}\text { North Sea (Scandina- } \\
\text { vian coast) }\end{array}$ & $\begin{array}{l}\text { Brattström } \\
(1936,1938 \\
1946,1947) \\
\text { Bresciani \& Jes- } \\
\text { persen }(1985)\end{array}$ \\
\hline $\begin{array}{l}\text { Ulophysema } \\
\text { pourtalesiae }\end{array}$ & Pourtalesia jeffreysi (E) & Coelomic cavity & $\begin{array}{c}\text { I or } 2 \text { ascothoricids } \\
\text { echinoid }^{-1}\end{array}$ & $\begin{array}{l}\text { N Atlantic (between } \\
\text { Norway. Spitzberg, } \\
\text { Greenland and the } \\
\text { Faroes) }\end{array}$ & $\begin{array}{l}\text { Brattström } \\
(1937)\end{array}$ \\
\hline $\begin{array}{l}\text { Waginella } \\
\text { metacrinicola }\end{array}$ & $\begin{array}{l}\text { Metacrinus rotundus } \\
\text { (O) }\end{array}$ & On stalk & - & Sea of Japan & $\begin{array}{l}\text { Okada (1926, } \\
\text { 1938), Grygier } \\
\text { (1983b) }\end{array}$ \\
\hline $\begin{array}{l}\text { Waginella } \\
\text { axotremata }\end{array}$ & $\begin{array}{l}\text { Metacrinus acutus, } \\
\text { Metacrinus angulatus, } \\
\text { Metacrinus cingulatus } \\
\text { (C) }\end{array}$ & On cirri & - & Indonesia; China Sea & Grygier (1983b) \\
\hline
\end{tabular}

According to Mortensen (1943a) and Suzuki \& Takeda (1974) an obvious parasitic relation occurs between the parthenopid crab Zebrida adamsi and several echinoid species (Table 4 ). the crab feeds on appendages, skin and peripheral dermal tissue of echinoids, producing conspicuous naked test areas. Similar parasitic behavior also occurs with some species of Dissodactylus living on clypeasteroid and spatangoid echinoids (Dexter 1977, Telford 1982, Bell \& Stancyk 1983). Telford (1982) reported that, depending on the species studied, the associated Dissodactylus take 50 to $100 \%$ of their diet from host tissues. According to him differences in feeding habits can be attributed partly to the structure of host spines, viz. larger test areas are denuded if the spines of the echinoid host are more porous (Fig. 7).
Gut-inhabiting species may produce deformations that are sometimes very conspicuous. Verrill (1867) reported that Pinnotheres chilensis considerably distends the rectal wall of the echinoid Coenocentrotus gibbosus to form a membranous cyst. The cyst attaches aborally to the echinoid body wall and extends near the mouth into the coelomic cavity. The anal area of the host is depressed and distorded, and the echinoid test is usually swollen on the side over the cyst (Fenucci 1967). P. chilensis parasitizes both $C$. gibbosus and Loxechinus albus. According to Mortensen (1943b) the crab does not induce major test deformation when infesting $L$. albus. Similar but less conspicuous deformations are caused also by Echinoecus convictor, E. pentagonus and E. rathbunae (respectively Bouvier \& Seurat 1905, Castro 1971, Miyake 1939), all of them producing 


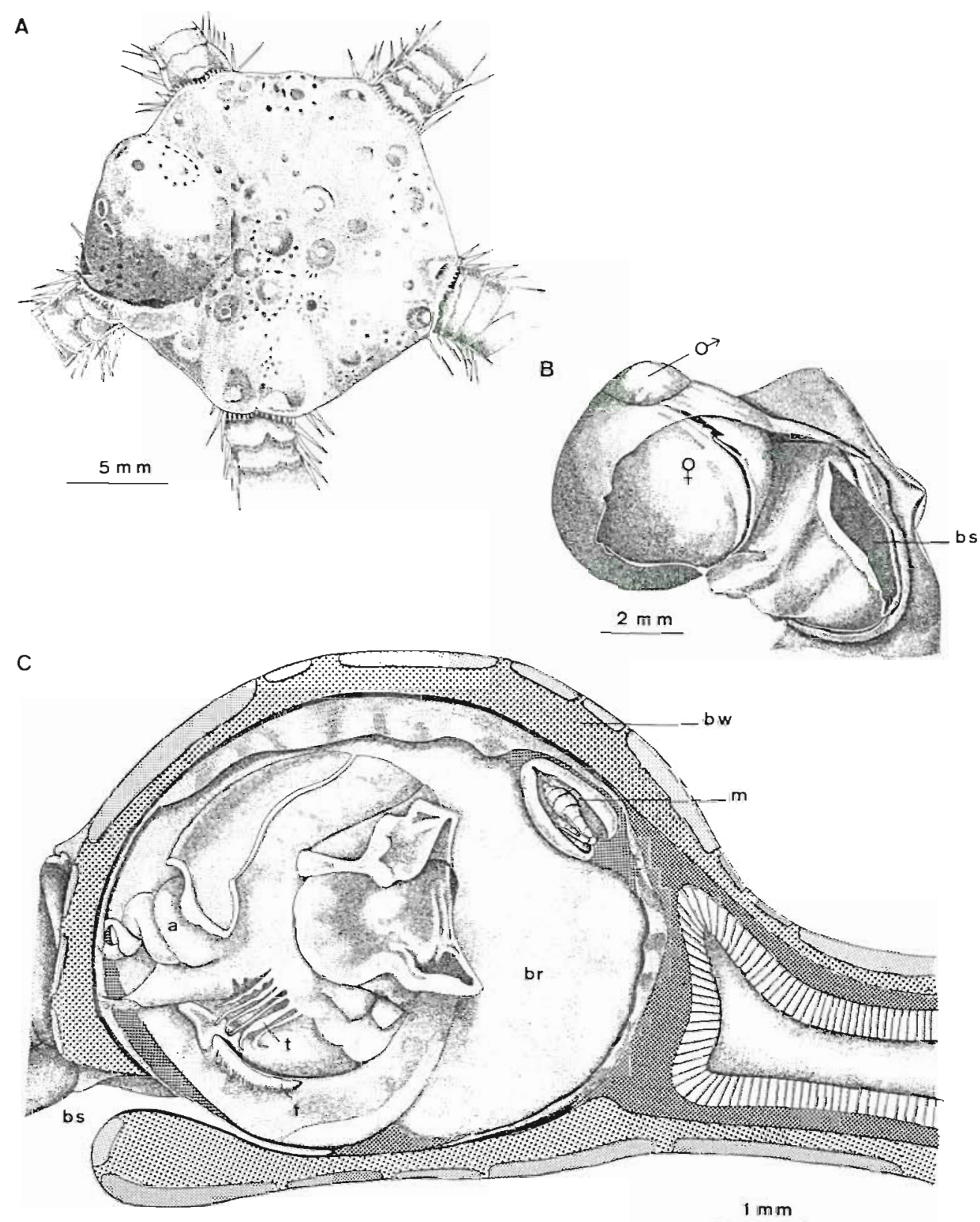

Fig. 5. Ascothorax ophioctenis, an ascothoracid parasite of the genital bursae of the ophiuroid Ophlocten sericeum (A) Aboral view of disc of an infested ophiuroid. (B) Dissected genital bursa contaning a paur of $A$. ophoctenis (C) Dlagramatic drawing of parasites in situ. a: antennule; br: brood pouch. bs bursal slıt, bw ophurold body-wall, f furca, $m$ dwarf male; thoracıc limbs (Redrawn from Wagin 1946; slightly modified)

swellings of anal tube and periproct of their host.

According to Suzuki \& Takeda (1974) and Dexter (1977), infestations by ectoparasitic crabs often exert major effects and may kill echinoids. The crabs select a particular site on the host's body surface and clear away the spines of the region (see also Telford 1982). This produces an obvious decrease in movements and spine activities of infested regular echmoids (Suzuki \& Takeda 1974). Dexter (1977) observed a reduction in spine activity which decreased the ability of clypeasterouds to feed and to move about in aquaria, resulting in a substantial increase in mortality.

\section{Agents: Arachnida; Pycnogonida; Insecta}

The only arachnid reported to be an echunoderm parasite is the acarian Enterohalacarus minutipalpus 

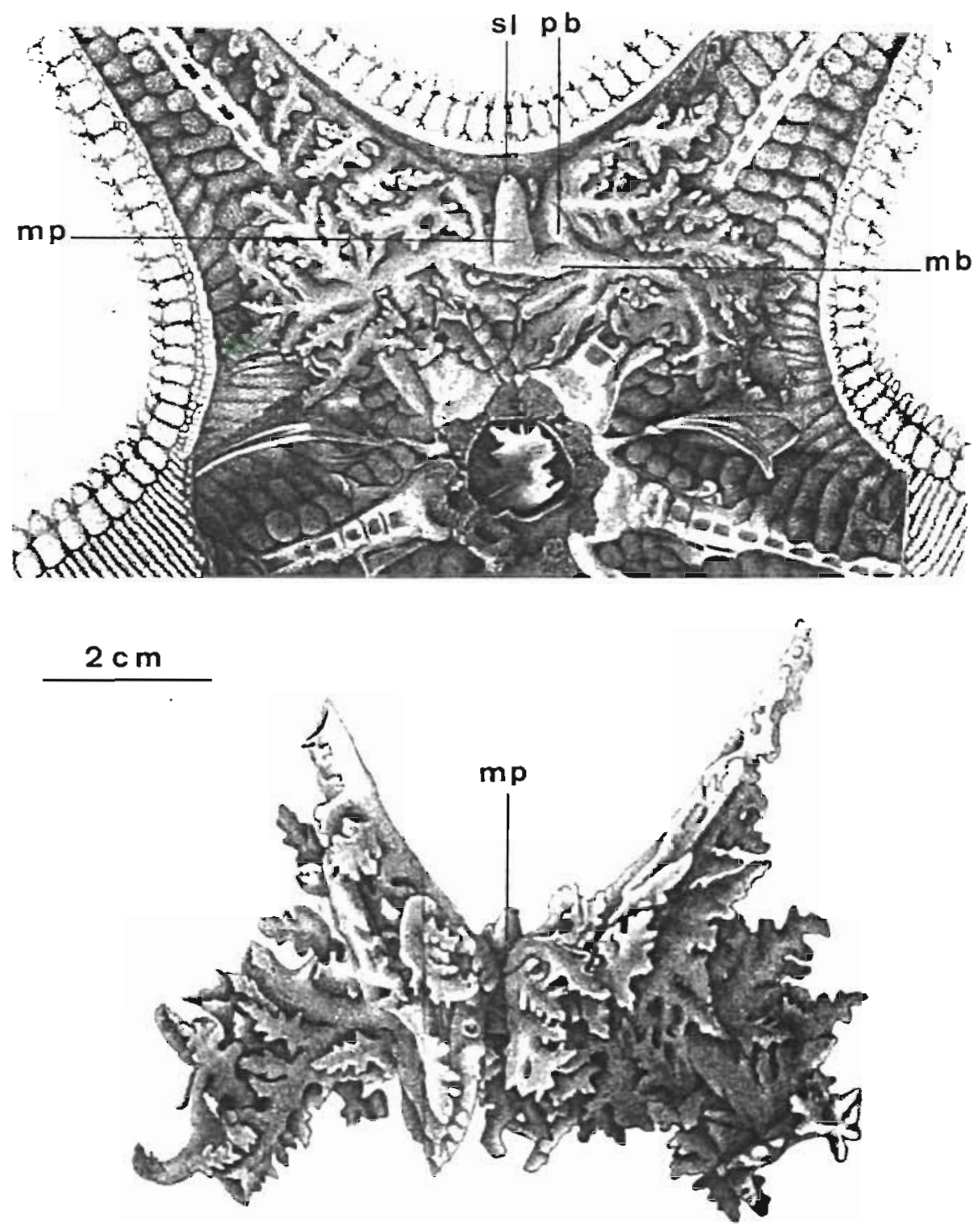

Fig. 6. Dendrogaster arborescens, an ascothoracid parasite of the coelomic cavity of the asteroid Dipsacaster sladeni. mb: main branch; mp: middle piece; $\mathrm{pb}$ : primary branch; sl: distal slit. (After Le Roi 1907) found in the gut of the echinoid Plesiodiadema indicum (Viets 1939). Three specimens were collected in echinoid material dredged by the Albatross off North Moluccas, Indonesia. Northing is known about hostassociate relations.

Pycnogonid-echinoderm associations have been noticed by several authors who generally suggested an ectoparasitic relation. Associations with holothuroids were observed by Prell (1910; Pycnogonum littorale/ Cucumaria frondosa) and Ohshima (1927; Lecythrorhynchus hilgendorfi/Holothuria lubrica). According to Ohshima, a single host may carry up to 30 pycnogonids which supposedly absorb the blood or 'body juice' of the holothuroid. An obvious pycnogonid-ophiuroid association occurs at Aldabra (Indian Ocean) with 3 species of Ophioderma and the seaspider, Anoplodactylus ophiurophilus (Sloan 1979, Sloan et al. 1979, Stock 1979). Sloan reported various infestation levels - from 3.6 to $83.7 \%$ - depending on the host species. He presented evidence that $A$. ophiurophilus has the potential to feed on the host's tube feet. The occurrence of pycnogonids on echinoids and asteroids has also been reported casually (Stock 1981).

An unexpected association between the marine trichopter Philanisus plebeius and the asteroids Patiriella exigua and Patiriella regularis was reported by Anderson et al. (1976) and by Winterbourn \& Anderson (1980). Caddis fly eggs were found in the asteroid coelomic cavity. Singly or in small clumps, eggs occur loose within the coelom close to the peristome or enveloped in stomach folds. The authors presumed that eggs are deposited through the respiratory papulae and that newly hatched intracoelomic larvae leave the host either via the same route or through the stomach wall. According to Winterbourn \& Anderson (1980), 
Table 4. Parasitic decapods (Reptantia) of echinoderms (compiled from the sources indicated). Hosts: E, echinoid; H, holothuroid

\begin{tabular}{|c|c|c|c|c|c|}
\hline Reptant & Host & Location on/in host & Remarks & Geographical area & Source \\
\hline $\begin{array}{l}\text { Dissodactylus } \\
\text { calmani }\end{array}$ & $\begin{array}{l}\text { Clypeaster rosaceus } \\
\text { (E) }\end{array}$ & $\begin{array}{l}\text { Outer body surface } \\
\text { (oral surface) }\end{array}$ & $\begin{array}{l}\text { Intestation level } 25 \text { to } \\
50 \%\end{array}$ & $\begin{array}{l}\text { Tropical W Atlantic } \\
\text { (Flonda, Jamaica) }\end{array}$ & Telford (1982) \\
\hline $\begin{array}{l}\text { Dissodactylus } \\
\text { crinitichelis }\end{array}$ & $\begin{array}{l}\text { Mellita sexiesperforata } \\
\text { (E) }\end{array}$ & Outer body surface & $\begin{array}{l}\text { Infestation level } 30 \text { to } \\
60 \%\end{array}$ & $\begin{array}{l}\text { Tropical W Atlantic } \\
\text { (Barbados) }\end{array}$ & $\begin{array}{l}\text { Telford (1978, } \\
1982)\end{array}$ \\
\hline $\begin{array}{l}\text { Dissodactylus } \\
\text { encopei }\end{array}$ & Encope emarginata (E) & Outer body surface & - & $\begin{array}{l}\text { Tropical W Atlantic } \\
\text { (Florida to N Brazil) }\end{array}$ & Rathbun (1918) \\
\hline $\begin{array}{l}\text { Dissodactylus } \\
\text { glassellh }\end{array}$ & $\begin{array}{l}\text { Mellita } \\
\text { longifissa (E) }\end{array}$ & Outer body surface & - & $\begin{array}{l}\text { Tropical E Pacific } \\
\text { (Mexican coast) }\end{array}$ & Rioja (1944) \\
\hline $\begin{array}{l}\text { Dissodactylus } \\
\text { lockingtoni }\end{array}$ & $\begin{array}{l}\text { Mellita longifissa, En- } \\
\text { cope micropora, En- } \\
\text { cope grandis, Encope } \\
\text { californica (E) }\end{array}$ & $\begin{array}{l}\text { Outer body surface } \\
\text { (proximal portion of } \\
\text { posterior interam- } \\
\text { bulactal lunule) }\end{array}$ & - & $\begin{array}{l}\text { Tropical E Pacific } \\
\text { (Northern Mexico) }\end{array}$ & Glassell (1935) \\
\hline $\begin{array}{l}\text { Dissodactylus } \\
\text { mellitae }\end{array}$ & $\begin{array}{l}\text { Mellita quinquiesper- } \\
\text { forata, Echınarachnius } \\
\text { parma (E) }\end{array}$ & Outer body surface & $\begin{array}{l}13 \text { crabs collected } \\
\text { from } 50 \mathrm{M} \text {. quinquies- } \\
\text { perforata (Pearse); al- } \\
\text { most } 100 \% \text { infesta- } \\
\text { tion (Johnson) }\end{array}$ & $\begin{array}{l}\text { NW Atlantic } \\
\text { (Massachusetts to } \\
\text { Florida) }\end{array}$ & $\begin{array}{l}\text { Rathbun (1918), } \\
\text { Pearse (1947), } \\
\text { Johnson (1952), } \\
\text { Gray et al. } \\
\text { (1968), Telford } \\
\text { (1982) }\end{array}$ \\
\hline $\begin{array}{l}\text { Dissodactylus } \\
\text { nitidus }\end{array}$ & $\begin{array}{l}\text { Encope stokesi, En- } \\
\text { cope micropora }(\mathrm{E})\end{array}$ & $\begin{array}{l}\text { Outer body surface } \\
\text { (near lunule or margi- } \\
\text { nal slits) }\end{array}$ & $\begin{array}{l}1 \text { to } 2 \text { crabs host }^{-1} ; \text { in- } \\
\text { fest mostly large } \\
\text { echinoids (diameter } \\
>30 \mathrm{~mm} \text { ) }\end{array}$ & $\begin{array}{l}\text { Tropical E Pacific } \\
\text { (Panama) }\end{array}$ & Dexter (1977) \\
\hline $\begin{array}{l}\text { Dissodactylus } \\
\text { primitivus }\end{array}$ & $\begin{array}{l}\text { Meoma ventricosa, } \\
\text { Plagiobrissus grandis } \\
\text { (E) }\end{array}$ & $\begin{array}{l}\text { Outer body surface } \\
\text { (mostly on oral surface) }\end{array}$ & $\begin{array}{l}\text { Infestation level } 79 \text { to } \\
100 \%\end{array}$ & $\begin{array}{l}\text { Tropical W Atlantic } \\
\text { (Barbados, Jamaica) }\end{array}$ & $\begin{array}{l}\text { Telford (1978, } \\
1982)\end{array}$ \\
\hline $\begin{array}{l}\text { Dissodactylus } \\
\text { smithi }\end{array}$ & Mellita longifissa (E) & Outer body surface & - & $\begin{array}{l}\text { Tropical L Pdcific } \\
\text { (Mexican coast) }\end{array}$ & Rioja (1944) \\
\hline $\begin{array}{l}\text { Dissodactylus } \\
\text { xantus! }\end{array}$ & $\begin{array}{l}\text { Encope stokesi, En- } \\
\text { cope micropora (E) }\end{array}$ & $\begin{array}{l}\text { Outer body surface } \\
\text { (near lunule or margi- } \\
\text { nal slits) }\end{array}$ & $\begin{array}{l}\text { More often on E. mic- } \\
\text { ropora }\end{array}$ & $\begin{array}{l}\text { Tropical th Pacific } \\
\text { (1'undmal }\end{array}$ & Dexter (1977) \\
\hline $\begin{array}{l}\text { Echinoecus } \\
\text { convictor }\end{array}$ & $\begin{array}{l}\text { Echinothrix diadema } \\
\text { (E) }\end{array}$ & $\begin{array}{l}\text { Internal swelling of } \\
\text { anal tube }\end{array}$ & - & $\begin{array}{l}\text { Tropical Indo-West } \\
\text { Pacific (Gambier Is- } \\
\text { land; Mauritius) }\end{array}$ & $\begin{array}{l}\text { Bouvier \& Seu- } \\
\text { rar }(1905), \text { Mor- } \\
\text { tensen }(1940)\end{array}$ \\
\hline $\begin{array}{l}\text { Echinoecus } \\
\text { pentagonus }\end{array}$ & $\begin{array}{l}\text { Pseudocentrotus de- } \\
\text { pressus, Anthocidaris } \\
\text { crassispina, Echino- } \\
\text { thrix calamaris, } \\
\text { Echinothrix diadema } \\
\text { (E) }\end{array}$ & $\begin{array}{l}\text { Outer body surface } \\
\text { (near peristome) }\end{array}$ & $\begin{array}{l}10 \text { crabs collected on } \\
48 \text { P. depr'ssus } \\
\text { (Suzuk1 \& Takeda) }\end{array}$ & $\begin{array}{l}\text { Tropical Indo-W } \\
\text { Pacific (Andaman, } \\
\text { Hawaii, Japan: coast of } \\
\text { Uchida) }\end{array}$ & $\begin{array}{l}\text { Castro (1971, } \\
\text { 1978). Suzuki \& } \\
\text { Tekeda (1974) } \\
\text { Sastry (1977, } \\
\text { 1981) }\end{array}$ \\
\hline $\begin{array}{l}\text { Echmeocus } \\
\text { rathbunae }\end{array}$ & $\begin{array}{l}\text { Echinothrix calamaris, } \\
\text { Phyllacanthus dubius } \\
\text { (E) }\end{array}$ & $\begin{array}{l}\text { Internal swelling of the } \\
\text { anal tubes }\end{array}$ & - & $\begin{array}{l}\text { NW Pacific (Ogasa- } \\
\text { wara Islands) }\end{array}$ & Miyake (1939) \\
\hline $\begin{array}{l}\text { Lissocarcinus } \\
\text { orbiculalus }\end{array}$ & Bohadschia argus $(\mathrm{H})$ & $\begin{array}{l}\text { Mainly respiratory } \\
\text { trees, also cloaca }\end{array}$ & $\begin{array}{l}11 \text { holothuroids in- } \\
\text { fested (61 investi- } \\
\text { gated) }\end{array}$ & $\begin{array}{l}\text { NW Pacific (Philippi- } \\
\text { nes: Puerto Galera) }\end{array}$ & $\begin{array}{l}\text { Trott \& Garth } \\
(1970)\end{array}$ \\
\hline $\begin{array}{l}\text { Lissocarcinus } \\
\text { ornatus }\end{array}$ & Holothuria sp. $(\mathrm{H})$ & Cloaca & - & $\begin{array}{l}\text { N Indian Ocean (An- } \\
\text { daman Sea) }\end{array}$ & Chopra (1931) \\
\hline $\begin{array}{l}\text { Ophisthopus } \\
\text { transversus }\end{array}$ & $\begin{array}{l}\text { Parastichopus califor- } \\
\text { nicus }(\mathrm{H})\end{array}$ & Cloaca & $\begin{array}{l}\text { Occur also in other in- } \\
\text { vertebrates (e.g., } \\
\text { bivalve molluscs) }\end{array}$ & NE Pacific (California) & Rathbun (1918) \\
\hline $\begin{array}{l}\text { Pinnaxodes } \\
\text { chilensis' }\end{array}$ & $\begin{array}{l}\text { Loxechinus albus, } \\
\text { Coenocentrotus } \\
\text { gibbosus (E) }\end{array}$ & $\begin{array}{l}\text { Partly embedded in } \\
\text { rectum wall }\end{array}$ & $\begin{array}{l}1 \text { to } 2 \text { crabs } \\
\text { echinoid }{ }^{-1} \text {. Infesta- } \\
\text { tion generally very } \\
\text { high ( } 90 \text { to } 100 \%) \\
\text { (Verrill, Clark, Rath- } \\
\text { bun, Schwabe) }\end{array}$ & $\begin{array}{l}\text { SE Pacific (Ecuador to } \\
\text { Patagonia) }\end{array}$ & $\begin{array}{l}\text { Verrill (1867), } \\
\text { Ortmann (1894), } \\
\text { Meissner (1896), } \\
\text { Clark (1910), } \\
\text { Rathbun (1918), } \\
\text { Schwabe (1936), } \\
\text { Mortensen } \\
\text { (1943b), Fenucci } \\
\text { (1967) }\end{array}$ \\
\hline $\begin{array}{l}\text { Pinnixa } \\
\text { barnhartj }\end{array}$ & Molpadia arenicola $(\mathrm{H})$ & Cloaca & - & NE Pacific (California) & Rathbun (1918) \\
\hline Pinnixa timida & Caudina chilensis $(\mathrm{H})$ & Cloaca & Infestation level $75 \%$ & $\begin{array}{l}\text { NW Pacific (Japan: } \\
\text { Mutsu Bay) }\end{array}$ & Tao $(1930)$ \\
\hline $\begin{array}{l}\text { Pinnotheres } \\
\text { decanus }\end{array}$ & Holothuria scabra $(\mathrm{H})$ & $\begin{array}{l}\text { Cloaca and respiratory } \\
\text { trees; rarely in the } \\
\text { coelomic cavity }\end{array}$ & $\begin{array}{l}10 \text { holothuroids in- } \\
\text { fested ( } 25 \text { investi- } \\
\text { gated) }\end{array}$ & $\begin{array}{l}\text { N Indian Ocean (In- } \\
\text { dian coast) }\end{array}$ & $\begin{array}{l}\text { Chopra (1931), } \\
\text { Jones \& } \\
\text { Mahadevan } \\
\text { (1965), Adithiya } \\
\text { (1969) }\end{array}$ \\
\hline
\end{tabular}


Table 4 (continued)

\begin{tabular}{|c|c|c|c|c|c|}
\hline Reptant & Host & Location on/1n host & Remarks & Geographical area & Source \\
\hline $\begin{array}{l}\text { Pinnotheres } \\
\text { setnai }\end{array}$ & $\begin{array}{l}\text { Unidentified } \\
\text { holothuroid }\end{array}$ & Respiratory trees & - & $\begin{array}{l}\text { NW Indian Ocean (An- } \\
\text { daman Sea) }\end{array}$ & Chopra $\{1931\}$ \\
\hline $\begin{array}{l}\text { Pinnotheres } \\
\text { villosissimus }\end{array}$ & $\begin{array}{l}\text { Actinopyga mauritia- } \\
\text { na, Actnopyga lecan- } \\
\text { ora }(\mathrm{H})\end{array}$ & Cloaca & - & $\begin{array}{l}\text { NW Indian Ocean (An- } \\
\text { daman Sea; west coast } \\
\text { of Sumatra) }\end{array}$ & $\begin{array}{l}\text { Doflein (1904), } \\
\text { Chopra (1931) }\end{array}$ \\
\hline Zebrda adamsi & $\begin{array}{l}\text { Diadema setosum, } \\
\text { Tripneustes gratilla, } \\
\text { Toxopneustes pileolus, } \\
\text { Toxopneustes elegans, } \\
\text { Asthenosoma ijimai, } \\
\text { Salmacis sphaeroides } \\
\text { (E) }\end{array}$ & $\begin{array}{l}\text { Outer body surface } \\
\text { (near ambitus) }\end{array}$ & $\begin{array}{l}\text { As a rule } 1 \text { crab } \\
\text { echinoid }{ }^{-1} \text { (11 crabs } \\
\text { collected) (Suzuki \& } \\
\text { Takeda) }\end{array}$ & $\begin{array}{l}\text { NW Pacific (Japan: } \\
\text { Suruga Bay, coast of } \\
\text { Thalland) }\end{array}$ & $\begin{array}{l}\text { Rathbun (1910), } \\
\text { Mortensen } \\
\text { (1943a), Suzuki } \\
\text { \& Takeda } \\
\text { (1974), Daniel \& } \\
\text { Krishnan (1978) }\end{array}$ \\
\hline
\end{tabular}

eggs are found in the coelom during most of the year. the infestation level being about $10 \%$.

\section{Agents: Pisces}

Associations between echinoderms and carapid fishes (pearlfishes) are of particular interest as they concern - at least in a few cases - typical parasitic relations between an invertebrate host and a vertebrate associate. The systematics, general biology, and ecology of pearlfishes are documented satisfactorily, and some species have been studied in detail (e.g. Zankert
1940, Arnold 1956, Trott 1970, Van Meter \& Ache 1974 Smith et al. 1981, Trott 1981). Pearlfish species associate with holothuroids and asteroids are listed in Table 5.

Most authors report that the stomach contents of Carapus spp. from echinoderm coelomic cavities do not show remains of host tissue (e.g. Trott 1970, Smith et al. 1981). Carapus spp. are predators. Basically, they use the host's coelom as shelter (Fig. 8). They leave it in order to catch prey, feeding primarily on crustaceans. Casual observations of feeding by Carapus on the host's gonad have been reported however (Hipeau-

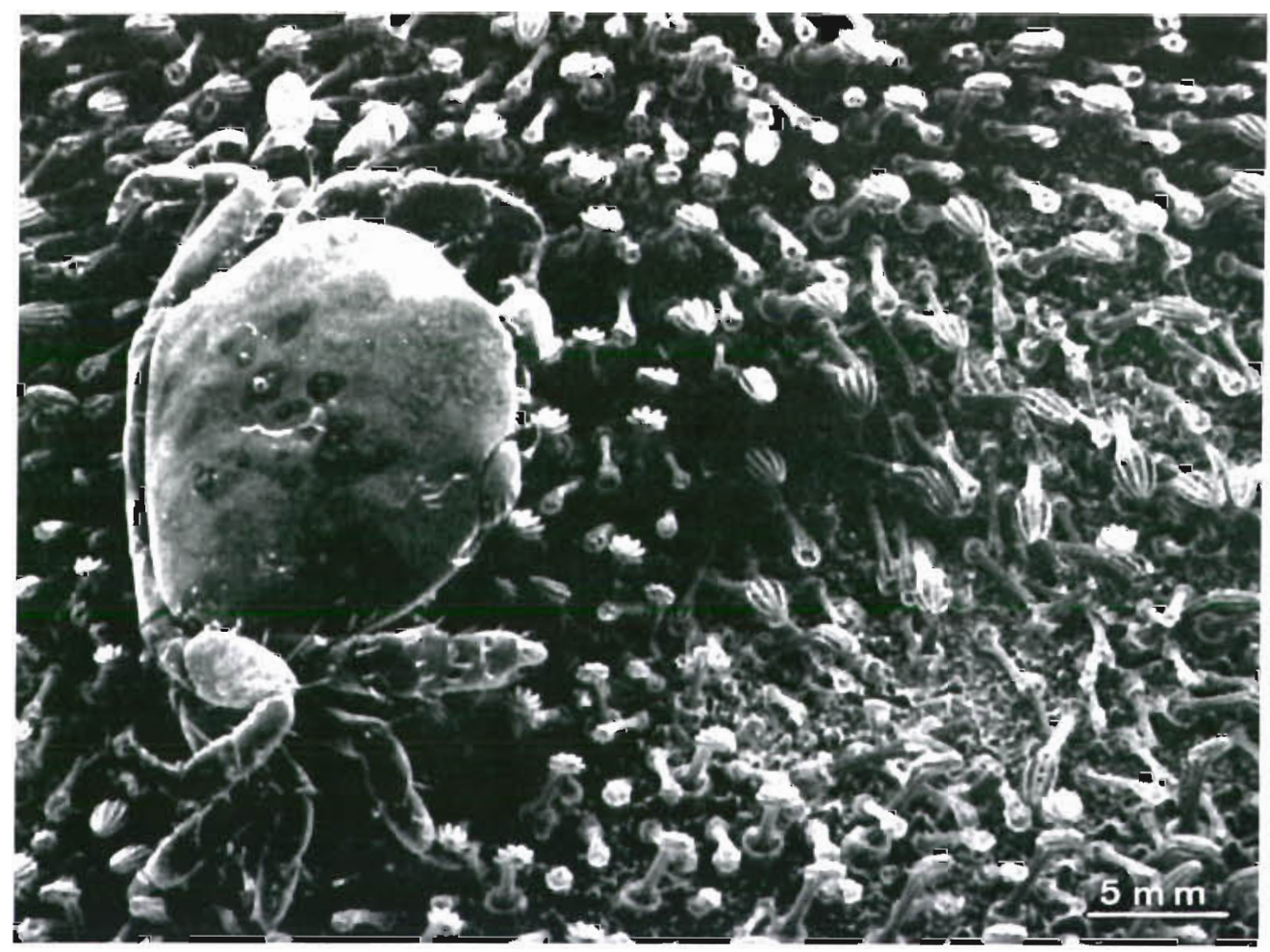

Fig. 7 Dissodactylus crinitichelis, an ectoparasitic crab of the clypeastroid echinoid Mellita sexiesperforata. The crab is seen beside the devastated area where it had been feeding. (After Telford 1982) 
Table 5. Fishes endosymbiotic in echinoderms (compiled from the sources indicated). Hosts: A, asteroid $H_{\text {, holothuroid }}$

\begin{tabular}{|c|c|c|c|c|c|}
\hline Fish & Host & Location in host & Remarks & Geographical area & Source \\
\hline Carapus acus & $\begin{array}{l}\text { Holothuna tubulosa, } \\
\text { Stichopus regalls }(\mathrm{H})\end{array}$ & $\begin{array}{l}\text { Mostly coelomic cavity; } \\
\text { sometimes respiratory } \\
\text { trees or cloaca }\end{array}$ & $\begin{array}{l}29 \text { infested } \\
\text { holothurolds (89 in- } \\
\text { vestigated) (Arnold) }\end{array}$ & $\begin{array}{l}\text { Mediterranean Sea } \\
\text { (mostly western part) }\end{array}$ & $\begin{array}{l}\text { Emery }(1880), \\
\text { Zanker }(1940), \text { Ar- } \\
\text { nold }(1953,1956), \\
\text { Gustato }(1977)\end{array}$ \\
\hline $\begin{array}{l}\text { Carapus } \\
\text { bermudensis }\end{array}$ & $\begin{array}{l}\text { Actmopyga agassizl } \\
\text { (usual host); also As- } \\
\text { tichopus multifidus, } \\
\text { Holothuria glaberrima, } \\
\text { Holothuria lentiginosa, } \\
\text { Holothuria princeps, } \\
\text { Isostichopus } \\
\text { badionotus, Thyonesp. } \\
\text { (H) }\end{array}$ & $\begin{array}{l}\text { Coelomic cavity; some- } \\
\text { times respratory trees }\end{array}$ & $\begin{array}{l}1 \text { to } 10 \text { fishes } \\
\text { holothurord '(mostly } \\
\text { 1); infestation level } \\
\text { may reach } 50 \% \\
\text { (Smith et al.) }\end{array}$ & $\begin{array}{l}\text { W Atlantic from Brazil } \\
\text { to North to Bermuda }\end{array}$ & $\begin{array}{l}\text { Linton (1907), } \\
\text { Parker (1926), An- } \\
\text { cona-Lopez } \\
\text { (1956). Smith \& } \\
\text { Tyler (1969). Trott } \\
\text { (1970). Dawson } \\
\text { (1971), Koster \& } \\
\text { Caycedo (1979), } \\
\text { Smith et al. (1981) }\end{array}$ \\
\hline $\begin{array}{l}\text { Carapus } \\
\text { dubius }\end{array}$ & $\begin{array}{l}\text { Unidentified } \\
\text { holothuroid }\end{array}$ & Internal & - & $\begin{array}{l}\text { Tropical W Atlantic } \\
\text { (Caribbeans) }\end{array}$ & Putnam (1874) \\
\hline $\begin{array}{l}\text { Carapus } \\
\text { homei }\end{array}$ & $\begin{array}{l}\text { Stichopus chloronotus } \\
\text { and Bohadschia argus } \\
\text { (usual host); also in Ac- } \\
\text { tionpyga mauritiana, } \\
\text { Holothuria atra, } \\
\text { Thelonota ananas, } \\
\text { Stichopus tropicalis }(\mathrm{H})\end{array}$ & $\begin{array}{l}\text { Mostly coelomic cavity, } \\
\text { also respiratory trees }\end{array}$ & $\begin{array}{l}\text { Infestation level } 16 \text { to } \\
88 \% \text { according to } \\
\text { period of year } \\
\text { (Smith) }\end{array}$ & $\begin{array}{l}\text { Tropical Indo- } W \\
\text { Pacific }\end{array}$ & $\begin{array}{l}\text { Bedford (1899), } \\
\text { Fisher (1907), } \\
\text { Sivickis \& Doman- } \\
\text { tay (1928), Muker- } \\
\text { ji (1932), Smith } \\
\text { (1964), Hipeau- } \\
\text { Jacquotte (1967), } \\
\text { Trott (1970, 1981), } \\
\text { Trott \& Trott } \\
\text { (1972) }\end{array}$ \\
\hline $\begin{array}{l}\text { Carapus } \\
\text { mourlan! }\end{array}$ & $\begin{array}{l}\text { Culcita schmideliana } \\
\text { and Culcita novae- } \\
\text { guineae (usual hosts); } \\
\text { also Acanthaster plan- } \\
\text { ci, Chonaster } \\
\text { granulosus, Protoreas- } \\
\text { ter linck, Thromidia } \\
\text { seychellensis }{ }^{2} \text { (A) } \\
\text { Bohadschia argus (H) }\end{array}$ & $\begin{array}{l}\text { Coelomic cavity of as- } \\
\text { terolds; coelomic cavity } \\
\text { and respiratory trees of } \\
\text { holothuroids }\end{array}$ & $\begin{array}{l}1 \text { to } 2 \text { fishes as- } \\
\text { teroid }{ }^{-1} \text { Infestation } \\
\text { level may reach } \\
\text { about } 100 \% \text { (Mor- } \\
\text { tensen; Trott 1970) } \\
\text { A single B. argus } \\
\text { contained } 15 \text { fishes } \\
\text { (Meyer-Rochow } \\
\text { 1977) }\end{array}$ & $\begin{array}{l}\text { Tropical Indo-W } \\
\text { Pacific }\end{array}$ & $\begin{array}{l}\text { Putnam (1874), } \\
\text { Simpson \& Brown } \\
\text { (1910), Mortensen } \\
\text { (1923), Mukerji } \\
\text { (1932), Strasburg } \\
\text { (1961), Smith } \\
\text { (1964), Hipeau- } \\
\text { Jacquotte (1967), } \\
\text { Trott (1970), Trott } \\
\text { \& Trott (1972), } \\
\text { Cheney (1973). } \\
\text { Jangoux (1974), } \\
\text { Meyer-Rochow } \\
\text { (1977. 1979) }\end{array}$ \\
\hline $\begin{array}{l}\text { Jordanicus } \\
\text { gracilis }\end{array}$ & $\begin{array}{l}\text { Bohadschia argus (usu- } \\
\text { al host); also } \\
\text { Holothuria atra, } \\
\text { Holothuria scabra, } \\
\text { Stichopus chloronotus, } \\
\text { Thelonota ananas (H) } \\
\text { Culcita novaeguinea, } \\
\text { Acanthaster planci (A) }\end{array}$ & Coelomic cavity & $\begin{array}{l}\text { Infestation level may } \\
\text { reach } 30 \% \text { (Trott \& } \\
\text { Trott) }\end{array}$ & $\begin{array}{l}\text { Tropical Indo-W } \\
\text { Pacific }\end{array}$ & $\begin{array}{l}\text { Doleschall (1861), } \\
\text { Arnold (1956), } \\
\text { Strasburg (1961), } \\
\text { Smith (1964), Trott } \\
\text { (1970), Trott \& } \\
\text { Trott (1972), } \\
\text { Cheney (1973) }\end{array}$ \\
\hline $\begin{array}{l}\text { Jordanicus } \\
\text { sagamianus }\end{array}$ & $\begin{array}{l}\text { Holothuria monacaria } \\
\text { (H) } \\
\text { Certonardoa semire- } \\
\text { gularis }(\mathrm{A})\end{array}$ & $\begin{array}{l}\text { Intestine (?) of } \\
\text { holothuroid; coelomic } \\
\text { cavity of asteroid }\end{array}$ & $\begin{array}{l}\text { Infestation common } \\
\text { in H. monacaria } \\
\text { (Tanaka) }\end{array}$ & $\begin{array}{l}\text { NW Pacific (Japan: } \\
\text { Sagami, Misaki) }\end{array}$ & $\begin{array}{l}\text { Tanaka (1908), } \\
\text { Yosii (1928a) }\end{array}$ \\
\hline
\end{tabular}

Jacquotte 1967), and some authors suggested that juvenile individuals could depend on their host for food (Jangoux 1974, Meyer-Rochow 1979). In contrast, Encheliophis spp are considered true parasites which stay permanently in the echinoderm coelom feeding on host viscera (Strasburg 1961, Smith 1964).

Effects of pearlfish infestations are said to be practically non-existent except for Encheliophis spp. which 


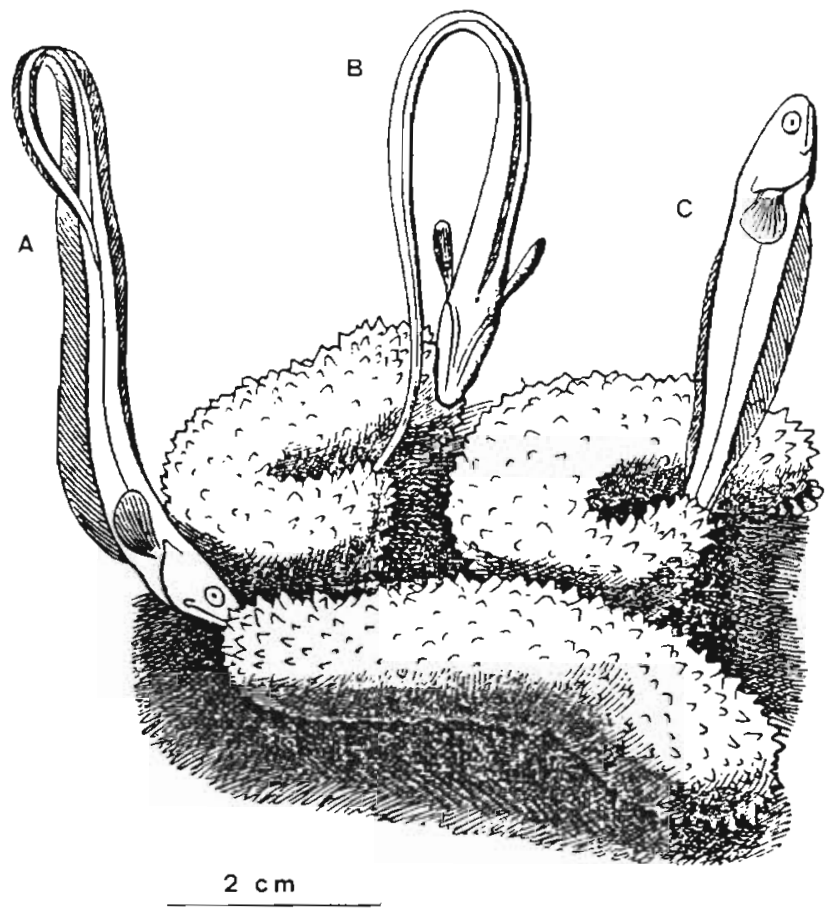

Fig. 8. Carapus acus penetrating the holothuroid Holothuria tubulosa. (A) Recognition. (B) Twisting. (C) Penetration. (After Emery 1880)

presumably cause castration by consuming the host's gonads. Carapus spp. cause only slight injury by piercing the host's digestive wall when entering or leaving the coelomic cavity. At low infestation levels the effect on the host should be negligible as pearlfishes do not always infest the same host, but shelter in the nearest suitable host found. However, in a higher infested echinoderm population (high infestation levels were, for example, recorded by Mortensen [1923] and Trott [1970] for Carapus mourlani inhabiting Culcita novaeguineae) chances increase that a given host is infested regularly; hence repeated loss of coelomic fluid and successive wound repairs have to be considered.

Acknowledgements. I thank Drs M. J. Grygier, O. Kinne and J. M. Lawrence for information and criticism; Dr C. Massin for helping with literature research; $N$. Biot, Dr G. Coppois, M. Doize and $M$. Klinkert for assisting in the preparation of the manuscript and illustrations.

\section{LITERATURE CITED}

Achituv, Y, (1971). Dendrogaster asterinae n. sp., an ascothoracid (Cirripedia) parasite of the starfish Asterina burtoni of the Gulf of Eilat. Crustaceana 21:1-4

Adithiya, L. (1969). Some notes on the anatomy of Holothuria. Loris 11: 385-388

Ancona-Lopez, A. A. (1956). Occorrência de Carapus Raf (= Fierasfer Oken) no Brasil.. Pap. Avuls. Dpto Zool (S. Paulo) 12: 389-397
Anderson, D. T., Fletcher, M. J., Lawson-Kerr, C. (1976). A marine caddis fly, Philanius plebeius, ovipositing in a starfish Patiriella exigua. Search 7: 483-484

Arendt, Y A. (1985). Biotic relations of crinoids Paleontol. Zh. USSR 1982(2): 69-76. (Russian; English summary)

Arnold, D. C. (1953). Observations on Carapus acus (Brünnich), (Jugulares, Carapidae). Pubbl. Staz. zool. Napoli 24: 152-166

Arnold, D. C. (1956). A systematic revision of the fishes of the teleost family Carapidae (Percomorphi, Blennioidea), with descriptions of two new species. Bull. Br. Mus. nat. Hist. 4: $247-307$

Barel, C. D., Kramers, P. G. (1970). Notes on associates of echinoderms from Plymouth and the coast of Brittany. Proc. K. ned. Akad. Wet. (C)73: 159-170

Barel, C. D., Kramers, P. G. (1977). A survey of the echinoderm associates of the north-east Atlantic area. Zool. Verh., Leiden 156: 1-159

Bartsrh, 1. (1982). Ophiuroidea (Echinodermata) from the Patagonian shelf. Mitt. zool. Mus. Hamb. 79: 211-250

Bay-Schmith, E., Jana, C. (1977). Balanus tintinabulum concinnus Darwin, 1854, epibionte poco comun del erizo negro, Tetrapygus niger (Molina, 1782). Boln Soc. Biol. Concepción 51: 59-61

Bedford, F. P. (1899). Holothurians. A. Willey's Zool. Results (London) 2: 141-150

Bell, J. L., Stancyk, S. E. (1983). Population dynamics and reproduction of Dissodactylus mellitae (Brachyura: innotheridae) on its sand dollar host, Mellita quinquiesperforata (Echinodermata). Mar. Ecol. Prog. Ser. 13: 141-149

Bocquet, $T$ (1952). Copépodes semi-parasites et parasites des échinodermes de la région de Roscoff. Bull. Soc. zool. Fr. 77: 495-504

Bonnier, J. (1898). Note sur le Pionodesmotes phormosomae, copépode parasite du Phormosoma uranus. Rés. Camp. scient. Albert I Monaco 12 (Appendice): 61-66

Boolootian, R. A. (1958). Notes on an unexpected association between a common barnacle and an echinoid. Bull. Sth Calif. Acad Sci. 57: 91-92

Boolootian, R. A. (1964). The occurrence of Balanus concavus on the test of Dendraster excentricus. Bull. Sth. Calif Acad. Sci. 63: 185-191

Bouvier, E. L., Seurat, G. (1905). Eumedon convictor crabe commensal d'un oursin. C.r. hebd. Séanc. Acad. Sci., Paris 140: 629-631

Brattström, H. (1936). Ulophysema oeresundense n. gen. et $\mathrm{sp}$. eine neue Art der Ordnung Cirripedia Ascothoracida. Ark Zool. 28A(23): 1-10

Brattström, H. (1937). On the genus Ulophysema Brattström with description of a new species from east Greenland. Meddr Gronland 118(7): 1-23

Brattström, H. (1938). Ascothoracica, eine für die norwegische Fauna neue Ordnung parasitischer Crustaceen. Det. Kong. Norske Vidensk. Selsk. Forh. 11(6): 22-25

Brattström, H. (1946). Observations on Brissopsis lyrifera (For bes) in the Gullmar Fjord. Ark. Zool. 37A(18): 1-25

Brattstrom, H. (1947). On the ecology of the ascothoracid Ulophysema oeresundense Brattström. Lunds Univ. Arsskr. (N.F. 2) 43(7): 1-75

Bresciani, J., Jespersen, A. (1985). The ultrastructure of the integument of Ulophysema oeresundense Brattstrom, 1936 (Crustacea, Ascothoracida). J. crust. Biol. 5: 146-159

Bresciani, J., Lützen, J. (1962). Parasitic copepods from the west coast of Sweden including some new or little known species. Vidensk Meddr dansk. naturh. Foren. 124 $367-408$

Brun, E. (1976). Ecology and taxonomic position of Henricia 
oculata Pennant. Thalassia jugosl. 12: 51-64

Campbell, A. C., Rainbow, P.S. (1977). The role of the pedicellariae in preventive barnacle settlement on the seaurchin test. Mar Behav. Physiol. 4: 253-260

Carpenter, P. H. (1889). Report on the Comatulae of the Mergui Archipelago, collected for the trustees of the Indian Museum, Calcutta, by Dr John Anderson, F.R.S., superintendent of the Museum. J. Linn. Soc., Zool. 21. $304-316$

Carton, Y (1968). Etude expérimentale de l'infestation d'Amphipholis squamata Delle Chiajei (ophiuride) par Cancerilla tubulata Dalyell (copépode cycloide). Cah. Biol. mar 9: 269-284

Carton, Y (1974). Copépodes parasites de Madagascar Il. Description de Botulosoma endoarrhenum n. gen., n. sp. (Lichomolgidae) parasite d'Othilia purpurea (Echinodermata, Asteridae): étude de ses relations anatomiques avec l'hôte. Crustaceana 26: 65-79

Castro, P. (1971). Nutritional aspects of the symbiosis between Echinoecus pentagonus and its host in Hawaii, Echinothrix calmaris. In: Cheng, $\mathrm{T} C$. (ed.) Aspects of the biology of symbiosis. Univ. Press, Baltimore, p. 229-247

Castro, P. (1978). Settlement and habitat selection in the larvae of Echinoecus pentagonus (A. Milne Edwards), a brachyuran crab symbiotic with sea urchins. J. exp. mar Biol. Ecol. 34: 259-270

Changeux, J. P. (1958). Quelques caractères biologiques d'un copépode parasite d'holothuries: Allantogymus delamarei n. g. n. sp. C. r. hebd. Seanc. Acad. Sci. Paris 247: 961-964

Changeux, J. P. (1961). Contribution à l'étude des animaux associés aux holothurides. Vie Milieu 10 (Suppl.): 1-124

Changeux, J. P., Delamare-Deboutteville, C. (1956). Enterognathus comatulae Giesbrecht, 1900. Vie Milieu 7: 106-107

Cheney, D. P. (1973). Pearlfish (Carapidae) in Acanthaster planci (L.). Micronesica 9: 159

Chopra, B. (1931). On some decapod Crustacea found in the cloaca of holothurians. Rec. Indian Mus. 33: 303-324

Clark, A. H. (1921). A monograph of the existing crinoids. I. The comatulids (Part 2). Bull. U.S. natn. Mus. 82: 1-795

Clark, H. L. (1910). The echinoderms of Peru. Bull. Mus. comp. Zool. Harv. 52: 321-358

Clark, R. B. (1959). Capitella capitata as a commensal, with a bibliography of parasitism and commensalism in the polychaetes. Ann. Mag. nat. Hist. (12) 2: 433-438

Cuénot, L. (1892). Commensaux et parasites des échinodermes (deuxième note). Rev. biol. Nord France 5: 1-22

Cuénot, L. (1912). Contribution à la faune du Bassin d'Arcachon. $V$ Echinodermes. Bull. Stn biol. Arcachon 14: $17-116$

Daniel, A., Krishnan, S. (1978). A parthenopid crab, Zebrida adamsii White, 1847, inhabiting interspaces of spines of the sea urchin, Salmacis virgulata L. Agassiz, 1846. Bull. zool. Surv. India 1: 171-175

Dartevelle, E. (1940). Les 'rotules' de la côte occidentale d'Afrique. Bull. Inst. r colon. Belge 11: 175-198

Dawson, C. E. (1971). Records of the pearlfish, Carapus bermudensis in the northern Gulf of Mexico and of a new host species. Copeia 1971. 730-731

Dexter, D. M. (1977). A natural history of the sand dollar Encope stokesi L. Agassiz in Panama. Bull. mar. Sci. 27: $544-551$

Djakonov, M. D. (1914). Ascothorax ophioctenis n. g. et n. sp., a new endoparasite belonging to the Ascothoracida. Trudy imp. S. Petersb. Obshch. Estest. 45: 158-164. (Russian; German summary)

Doflein, F. (1904). Brachyura. Deutsche Tiefsee-Expedition 6: $1-314$
Dojiri, M., Humes, A. J. (1982). Copepods (Poecilostomatoidea: Taeniacanthidae) from sea urchins (Echinoidea) in the southwest Pacific. Zool. J. Linn. Soc. 74: $381-436$

Doleschall, C. L. (1861). On Oxybeles gracilis Bleeker. Ann. Mag. nat. Hist. (3) 7: 340-342

Edwards, C. L. (1891). Beschreibung einiger neuen Copepoden und eines neuen copepoden ähnlichen Krebses, Leukkartella paradoxa. Arch. Naturgesch. 57: 75-104

Emery, C. (1880). Le specie del genere Fierasfer nel Golfo di Napoli e regione limitrofe. Fauna Flora Golfes Neapel 2: $1-76$

Emson, R. H., Mladenov, P. V., Wilkie, I. C. (1985). Studies of the biology of the West Indian copepod Ophiopsyllus reductus (Siphonostomatoidea: Cancerillidae) parasitic upon the brittlestar Ophiocomella ophiactoides. J. nat. Hist. 19: 151-171

Fedotov, D. M. (1912). Protomyzostomum polynephris, eine neue Myzostomidenart. Zool. Anz. 39: 649-653

Fedotov, D. M. (1914). Die Anatomie von Protomyzostomum polynephris Fedotov. Z. wiss. Zool. 109: 631-696

Fedotov, D. M. (1916). On the parasitism of Protomyzostomum in Gorgonocephalus eucnemis M. Tr. Zool Zh. SSSR 1: 161-218. (Russian; English summary)

Fedotov, D. M. (1925). Über eine neue Art von Protomyzostomum (Pr. astrocladi, sp. n.) aus Astrocladus. Zool. Anz. 63: $183-194$

Fenucci, J. L. (1967). Contribucion al conocimiento del crustacea decapodo braquiuro Pinnaxodes chilensis (M. Edwards), comensal de Loxechinus albus (Molina) (Echinodermata, Echinoidea). Physis, B. Aires 27 - 125-133

Fewkes, J. W. (1887). A troublesome parasite of brittle starfish (Amphiura squamata). Nature, Lond. 37: 274-275

Fewkes, J. W. (1888). On a new parasite of Amphiura. Proc. Boston Soc. nat. Hist. 24: 31-33

Fishelson, L. (1973). Ecology of the crinoids of the northern Red Sea with emphasis on epi- and endozoic fauna associated with them. J. mar. biol. Ass. India 15: 461-473

Fishelson, L. (1974). Ecology of the northern Red Sea crinoids and their epi- and endozoic fauna. Mar. Biol. 26: 183-192

Fisher, W. K. (1907). The holothurians of the Hawaiian Islands. Proc. U.S. natn. Mus. 32: 637-744

Fisher, W. K. (1911). Asteroidea of the North Pacific and adjacent waters. Part I. Phanerozonia and Spinulosa. Bull. U.S. natn. Mus. 76(1): 1-419

Fisher, W. K. (1919). Starfishes of the Philippines seas and adjacent waters. Bull. U.S. natn. Mus. 100(3): 1-712

Fisher, W K. (1928). Asteroidea of the North Pacific and adjacent waters. Part II. Forcipulata (pars). Bull. U.S. natn. Mus. 76(2): 1-245

Fisher, W. K. (1930). Asteroidea of the North Pacific and adjacent waters. Part III. Forcipulata (concluded). Bull. U.S. natn. Mus. 76(3): 1-356

Fisher, W. K. (1940). Asteroidea. 'Discovery' Rep. 20: 69-306

Ganapati, P. N., Radhakrishna, Y. (1962). Inquilinism between a new hesionid polychaete and a holothurian Molpadia sp. Curr. Sci. 31: 382-383

Ganapati, P. N., Sastry, D. R. (1972). Record of Athanas indicus (Coutière) (Decapoda: Alpheidae) associated with Stomopneustes variolaris (Lamarck) (Echinodermata: Echinoidea) from Visakhapatnam coast. Proc. Indian Acad. Sci. (B) 38: 367-372

Giard, A. (1887). Sur un copépode (Cancerilla tubulata Dalyell), parasite de l'Amphiura squamata Delle Chiaje. C.r. hebd. Séanc. Acad. Sci. Paris 104: 1189-1192

Giesbrecht, W (1900). Mitteilungen über Copepoden. Mitt. zool. Stn Neapel 14:61-79 
Giltay, L. (1934). Note sur l'association de Balanus concavus pacificus Pilsbry (Cirripède) et Dendraster excentricus (Eschscholtz) (échinoderme). Bull. Mus. r Hist. nat. Belg. 10(5): $1-7$

Glassell, S. A. (1935). New or little known crabs from the Pacific coast of northern Mexico. Trans. San Diego Soc. nat. Hist. 8: 91-106

Gorzula, S. (1978). Collocheres elegans, a cyclostome copepod infesting Ophiocomina nigra in the Firth of Clyde. Western Natur. 7:67-77

Goudey-Perrière, F. (1979). Amphiurophilus amphiurae (Hérouard), crustacé copépode parasite des bourses génitales de l'ophiure Amphipholis squamata Delle Chiaje, échinoderme: morphologie des adultes et études des stades juvéniles. Cah. Biol. mar. 20: 201-230

Goudey-Perrière, F. (1980). Modalités de l'infestation de l'ophiure Amphipholis squamata Della Chiaje, échinoderme, par le crustacé copépode Amphiurophilus amphiurae (I lérouard) et influence du parasite sur l'état de gravidité de l'hôte. C.r. hebd. Séanc. Acad. Sci, Paris 291. $697-700$

Graff, L. von (1884). Report on the Myzostomida. Challenger Rep. Zool. 10: 1-82

Graff, L. von (1887). Report on the Myzostoma. Supplement. Challenger Rep. Zool. 20:1-16

Grainger, J. N. (1950). Notes on parasitic Crustacea. Ann. Mag. nat. Hist (12) 3: 635-638

Gray, I. E., McCloskey, L. R., Weihe, S. T (1968). The commensal crab Dissodactylus mellitae and its reaction to sand dollar host-factor. J. Elisha Mitchell scient. Soc. 84 $472-481$

Grygier, M. J. (1981). A representative of the genus Dendrogaster (Cirripedia: Ascothoracida) parasitic in an Antarctic starfish. Antarct. Res. Ser. 32: 1-15

Grygier, M. J. (1982). Dendrogaster (Crustacea: Ascothoracida) from California: sea-star parasites collected by the Albatross. Proc. Calif. Acad. Sci. 42: 443-454

Grygier, M. J. (1983a). Ctenosculum hawailense Heath: confirmation of its affinities (Crustacea: Ascothoracida - Ex Mollusca: Gastropoda) J. crust. Biol. 3: 257-265

Grygier, M. J. (1983b). Revision of Synagoga. (Crustacea: Maxillopoda: Ascothoracida). J. nat. Hist. 17: 213-239

Grygier, M. J. (1983c). Ascothorax, a review with descriptions of new species and remarks on larval development, biogeography, and ecology (Crustacea: Ascothoracida) Sarsia 68: 103-126

Grygier, M. J. (1985a). Two species of Dendrogaster (Crustacea: Ascothoracida) parasitic in porcellanasterid starfishes. Galathea Rep. 16: 113-120

Grygier, M. J. (1985b). Résultats des campagnes Musorstom. Crustacea Ascothoracida. Mém. Mus. natn. Hist. nat., Paris (A) Zool. 133: 417-426

Grygier, M. J. (1986). Dendrogaster (Crustacea: Ascothoracida) parasitic in Alaskan and eastern Canadian Leptasterias (Asteroidea). Can. J. Zool. 64: 1249-1253

Grygier, M. J., Fratt, D. B. (1984). The ascothoracid crustacean Ascothorax gigas: redescription, larval development, and notes on its infestation of the Antarctic ophiuroid Ophionotus victoriae. Biol. Antarct. Seas $4143-58$

Grygier, M. J., Salvat, M. B. (1984). Dendrogaster argentinas sp. nov., a South American sea-star parasite. Proc biol Soc. Wash. 97: 43-48

Gustato, G. (1977). Osservazioni sulla biologia e sul comportamento di Carapus acus (Ophidioidea - Percomorphi) Boll. Soc. Nat. Napoli 85: 505-536

Hansen, H. J. (1902). Echinocheres globosus, n. gen., n. sp., a copepod parasitic in spines of an echinothurid. Vidensk.
Meddr dansk naturh. Foren. 1902: 437-499

Hara, J., Okada, Y (1921). Two new species of Myzostoma. Annotnes zool. jap. 10: 33-39

Heath, H. (1910). A new genus of parasitic gastropods. Biol. Bull. mar. biol. Lab., Woods Hole 1.8: 99-108

Heegard, P. (1951). Antarctic parasitic copepods and an ascothoracid cirriped from brittle-star Vidensk. Meddr dansk naturh. Foren. 113: 171-190

Hérouard, E. (1906). Sur un nouveau copépode parasite d'Amphiura squamata. C.r hebd. Séanc. Acad. Sci., Paris 142 $1287-1.289$

Hickmann, J. L. (1959). Dendrogaster tasmaniensis sp. nov. (Ascothoracida) from the sea-star Allostichaster polyplax (Müller and Troschel). Parasitology 49: 316-329

Hipeau-Jacquotte, R. (1967). Observations sur le comportement du poisson Carapidae Carapus homei (Richardson 1884) de Madagascar Recl Trav. Stn mar. Endoume 6 (Fasc. suppl.): 141-151

Humes, A. G. (1957). Deux copépodes harpacticoïdes nouveaux du genre Tisbe, parasite des holothuries de la Méditerranée. Vie Milieu 8: 9-22

Humes, A. C. (1968). Lecanarius kossmannianus, a new cyclopoid copepod parasitic in holothurians in Madagascar. Proc. biol. Soc. Wash. 81. 179-190

Humes, A. G. (1975). Cyclopoid copepods (Nanaspididae and Sabelliphilidae) associate with holothurians in New Caledonia. Smithson. Contr. Zool. 202: 1-41

Humes, A. G. (1979). Synapticola teres Voigt, 1892 (Copepoda, Cyclopoida, Sabelliphilidae) from a holothurian in northeastern Australia. Crustaceana 36: 249-256

Humes, A. G. (1980a). A review of the copepods associated with holothurians, including new species from the IndoPacific. Beaufortia 30: 31-123

Humes, A. G. (1980b). A new taeniacanthid copepod from the esophagus of a sea urchin in Queensland. Mem. Qd Mus. 20: $171-179$

Humes, A. G. (1986). Synopsis of copepods associated with asteroid echinoderms, including new species from the Moluccas. J. nat. Hist. 20: 981-1020

Humes, A. G., Ho, J. S. (1969). Cyclopoid copepods parasitic in holothurians in Madagascar. J. Parasit. 55: 877-894

Humes, A. G., Ho, J. S. (1970). The genus Diogenella (Copepoda, Cyclopoida) parasitic in holothurians in the West Indies. Crustaceana 19: 15-36

Humes, A. G., Ho, J. S. (1971). The genus Diogenidium (Copepoda, Cyclopoida) parasitic in holothurians in the West Indies. Crustaceana 20: 171-191

Hurley, A. C. (1973). Larval settling behaviour of the acorn barnacle (Balanus pacificus Pilsbry) and its relation to distribution. J. Anim. Ecol. 42: 599-609

Jägersten, G. (1940). Zur Kenntnis der Morphologie, Entwicklung und Taxonomie der Myzostoma. Nova Acta R. Soc. Scient. upsal. (4) 11(8): 1-84

Jangouy, M. (1974). Sur l'association' entre certaines astéries (Echinodermata) et des poissons Carapidae. Rev. Zool. afr. 88: 789-796

Jangoux, M. (1987a). Diseases of Echinodermata. I. Agents microorganisms and protistans. Dis. aquat. Org. 2: 147-162

Jangoux, M. (1987b). Diseases of Echinodermata. II. Agents metazoans (Mesozoa to Bryozoa). Dis. aquat. Org. 2: $205-234$

Johnson, I. S. (1952). The demonstration of a 'host-factor' in commensal crabs. Trans. Kans. Acad. Sci. 55: 458-464

Jones, S, Mahadevan, S. (1965). Notes on animal associations 5. The pea crab Pinnotheres deccanensis Chopra insıde the respiratory tree of the sea cucumber, Holothuria scabra Jäger. J. mar. biol. Ass. India 7: 377-380 
Jungersen, H. F. (1912). Chordeuma obesum, a new parasitic copepod endoparasite in Asteronyx loveni. Rep. Brit. Ass. Adv. Sci. 1912: 505-506

Jungersen, H. F. (1914). Chordeuma obesum, a new parasitic copepod endoparasitic in Asteronyx loveni M.Tr. Mindeskrift J. Steenstrup 1914(16): 1-19

Kenny, R. (1959). A new Australian record of an ascothoracid parasite. Aust. J. Sci. 21: 221

Kinne, O. (1980). Diseases of marine animals: general aspects. In: Kinne, $O$. (ed.) Diseases of marine animals, Vol. I. General aspects, Protozoa to Gastropoda. Wiley, Chicester, p. $13-73$

Knipowitsch, N. (1891). Dendrogaster astericola nov. gen. et sp., eine neue Form aus der Gruppe Ascothoracida. Biol. Zbl. 100: 707-711

Koehler, R. (1898). Echinides et ophiures provenant des campagnes du yacht l'Hirondelle (Golfe de Gascogne, Açores, Terre-Neuve). Rés. Camp. scient. Albert I Monaco 12: 1-78

Kossmann, R. (1877). Entomostracea (I. Theil: Lichomolgidae). Zool. Ergebn. Reise Kunstgeb. Roten Meeres (K. Acad. Wiss. Berlin) (1)4: 1-24

Korschelt, E. (1933). Über zwei parasitäre Cirripedien, Chelonibia und Dendrogaster, nebst Angaben über die Beziehungen der Balanomorphen zu ihrer Unterlage. Zool. Jb. (Abt. Syst.) 64: 1-40

Koster, F., Caycedo, I. E. (1979). Primer hallazgo de Astichopus multifidus (Echinodermata: Holothurioidea, Stichopodidae) y Carapus bermudensis (Pisces: Gadıformes, Carapidae) en el Caribe Columbiano, con notas sobre esta nueva associacion. Bol. Mus. Mar Bogota 9: 1-47

Kristensen, R. M. (1980). Zur Biologie des marinen Heterotardigraden Tetrakentron synaptae. Helgoländer Meeresunters. 34: 165-177

Le Calvez, J. (1938). Parachordeumium tetraceros n. gen. n. sp., copépode gallicole parasite d'une ophiure de Villefanche-sur-mer. C.r. Congr. Socs sav. Paris, Sect. Sci. 71 : 259-263

Le Roi, O. (1905). Zwei neue parasitische Cirripedien aus der Gruppe der Ascothoracida. Zool. Anz. 29: 399-401

Le Roi, O. (1907). Dendrogaster arborescens und Dendrogaster ludwigi, zwei entoparasitische Ascothoraciden. Z. wiss. Zool. 86: 100-133

Linton, E. (1907). Note on the habits of Fierasfer affinis. Am. Nat. $41 \quad 1-4$

Ludwig, H. (1905). Ein entoparasitischer Chaetopod in einer Tiefsee-Ophiure Zool. Anz. 29: 397-399

Madsen, E. J. (1961). The Porcellanasteridae. A monographic revision of an abyssal group of sea-stars. Galathea Rep. 4: $33-174$

Marenzeller, E. von (1895a). Myzostoma asteriae n. sp., ein Endoparasit von Asterias Arten. Anz. Akad. Wiss. Wien 18: 192-193

Marenzeller, E. von (1895b). Zoologische Ergebnisse. V. Echinodermen gesammelt 1893, 1894 (im östlichen Mittelmeere). K. Akad. Wiss. Wien (Math. Naturw. Cl.) 62: 123-148

Masson, C. (1965). Description morphologique de la femelle de Amphiurophilus, copépode parasite interne de Amphipholis squamata Chiaje. Proc. First intern. Congr. Parasitol. 2: 1078-1079

McClendon, J. F. (1906). The myzostomes of the Albatross expedition to Japan. Bull. Am. Mus. nat. Hist. 22: 119-130

Meissner, M. (1896). Die von Herrn Dr. Plate aus Chile heimgebrachten See-Igel. Arch. Naturgesch. 62: 84-90

Meyer, D. L., Ausich, W. 1. (1983). Biotic interactions among recent and among fossil crinoids. In: Tevesz, M. J. S., McCall, P. L. (ed.) Biotic interactions in recent and fossil benthic communities. Plenum Press, New York, p. 377-427
Meyer-Rochow, V B. (1977). Comparison between 15 Carapus mourlani in a single holothurian and 19 C. mourLani from starfish. Copeia 1977.582-584

Meyer-Rochow, V B. (1979) Stomach and gut content of Carapus mourlani from starfish and a holothurian. Annls. Zool. fenn. 16: 287-289

Miyake, S. (1939). Note on crabs of the genus Echinoecus Rathbun living commensally with echinoids. (Parthenopidae, Eumedoniidae). Annotnes zool. jap. 18: 83-94

Monticelli, F. S. (1892). Notizia preliminare intorno ad alcuni inquilini degli Holothuroidea del Golfo di Napoli. Monitore zool. ital. 3: 249-256

Moore, H. B., McPherson, B. F. (1963). Colonization of the Miami area by the barnacle Balanus trigonus Darwin and a note on its occurrence on the test of an echinoid. Bull. mar. Sci. 13: 418-421

Mortensen, $T$ (1912). Über Asteronyx loveni $M$. Tr $Z$. wiss. Zool. 101.264-289

Mortensen, $\uparrow$ (1923). The Danish expedition to the Kei Islands 1922. Vidensk. Meddr dansk naturh. Foren. 76: 55-100

Mortensen, T (1933). Echinoderms of South Africa (Asteroidea and Ophiuroidea). Vidensk. Meddr dansk naturh. Foren. 93: 215-400

Mortensen, T (1935). A Monograph of the Echinoidea. Part II. C. A. Reitzel, Copenhagen

Mortensen, T (1940). A Monograph of the Echinoidea. Part III(1) Aulodonta. C. A. Reitzel, Copenhagen

Mortensen, T. (1943a). A Monograph of the Echinoidea. Part III(2) Camarodonta I. C. A. Reitzel, Copenhagen

Mortensen, T (1943b). A Monograph of the Echinoidea. Part III(3) Camaradonta II. C. A. Reitzel, Copenhagen

Mortensen, T., Stephensen, K. (1918). On a gall-producing parasitic copepod, infesting an ophiurid. Vidensk. Meddr dansk naturh. Foren. 69: 261-275

Mukerji, D. D. (1932). Biological observations on and instances of commensalism of an ophioid fish with echinoderms of the Andaman Islands. Rec. Indian Mus. 34: 567-570

Ohshima, H. (1927). Notes on some pycnogons living semiparasitic on holothurians. Proc. imp. Acad. Japan 3: $610-613$

Okada, Y. (1922). On a new Protomyzostomum (P. sagamiense, sp. nov.) from ovary of Gorgonocephalus. Annotnes zool jap. 10: 165-169

Okada, Y (1925). Contribution à l'étude des cirripèdes ascothoraciques. I. Note sur le Dendrogaster arborescens Le Roi; établissement d'un nouveau genre. Bull. Mus. Hist. nat., Paris $31.364-371$

Okada, Y (1926). Contribution à l'étude des Cirripèdes ascothoraciques. II. Note sur l'organisation des Synagoga. Bull. Mus. Hist. nat., Paris 32: 69-73

Okada, Y. (1933). Mesomyzostoma katoi, n. sp., an interesting myzostome found in the gonad of Comanthus japonicus. Annotnes zool. jap. 14: 185-189

Okada, Y (1938). Les Cirripèdes ascothoraciques. Trav. Sta. zool. Wimereux 13: 489-514

Ortmann, A. (1894). Die Decapoden-Krebse des Strassburger Museums. Zool. Jb. 7: 683-772

Paris, J. (1955). Commensalisme et parasitisme chez les annélides polychètes. Vie Milieu 5: 525-536

Parker, G. M. (1926). The inquiline fish Fierasfer at Key West, Florida. Proc. natn. Acad. Sci. U.S.A. 12: 421-422

Paterson, N. F. (1958). External features and life cycle of Cucumaricola notabilis nov. gen. et sp., a copepod parasite of the holothurian. Cucumaria. Parasitology 48: 269-290

Pearse, A. S. (1947). On the occurrence of ectoconsortes on marine animals at Beaufort, N. C. J. Parasitol. 33: 453-458

Prell, H. (1910). Beiträge zur Kenntnis der Lebensweise 
einiger Pantopoden. Bergens Mus. Årb. 1909(10): 1-30

Prenant, M. (1959). Classe des Mysostomides. In: Grassé, P. P (ed.) Traité de Zoologie, 5(1). Masson, Paris, p. 714-784

Prouho, H. (1892). Sur deux myzostomes parasites de l'Antedon phalangium (Müller). C.r. hebd. Séanc. Acad. Sci., Paris 115: 846-849

Putnam, F. W (1874). Notes on Ophididae and Fierasferidae, with descriptions of new species from America and the Mediterranean. Proc. Boston Soc. nat. Hist. 16: 339-348

Pyefinch, K. A. (1940). The anatomy of Ophioica asymmetrica, sp. n., a copepod endoparasitic in an ophiuroid. J Linn. Soc. Lond. (Zool.) 41 1-19

Rathbun, M. J. (1910). The Danish expedition to Siam 1899-1900. V Brachyura. D. Kgl. Dansk Vidensk. Selsk. Skr. (7) 5: 301-368

Rathbun, M. J. (1918). The grapsoid crabs of America. Bull. U.S. natn. Mus. 97: 1-461

Remscheid, E. (1916). Beiträge zur Kenntnis der Myzostomiden. Abh. Senckenb. naturi. Ges. 35: 179-226

Rioja, E. (1944). Observaciones sobre algunas especies de cangrejas del genero Dissodactylus Smith (Braqiuros, Pinnoteridos) en las costas mexicanas del Pacifico. Anls. Inst. Biol. Univ. Mexico 15: 147-160

Röttger, R. (1969). Okologie und Postlarvalentwicklung von Scottomyzon gibberum, eines auf Asterias rubens parasitisch lebenden Copepoden (Cyclopoida, Siphonostoma). Mar. Biol. 2: 145-202

Röttger, R., Astheimer, H., Spindler, M., Steinborn, J. (1972) Ökologie von Asterocheres lilljeborgi, eines auf Henricia sanguinolenta parasitisch lebenden Copepoden. Mar. Biol. 13: $259-266$

Ruffo, S. (1957). Studi sui corstacei anfipodi. 19. Osservazioni sopra alcune specie di anfipodi trovate a Banyuls su echinodermi. Vie Milieu 8: 31.2-318

Sastry, D. R. (1977). On some crustacean associated of seauchins of the Andaman and Nicobar Islands. Newsl. zool. Surv. India 3: 119-120

Sastry, D. R. (1981). On some crustacean associates of Echinodermata from the Bay of Bengal. Rec. zool. Surv. India $79: 19-30$

Schulz, E. (1935). Actinarctus doryphorus nov. gen. nov. sp., ein merkwürdiger Tardigrad aus der Nordsee. Zool. Anz. 111: 285-288

Schwabe, G. H. (1936). Investigaciones sobre Loxechinus albus Mol. y Pinnotheres chilensis Edw. Boln Soc. Biol. Concepción 10: 125-137

Shoemaker, C. R. (1919). A new amphipod parasitic on a crinoid. Proc biol. Soc. Wash. 32: 245-246

Simpson, J. J., Brown, R. N. (1910). Asteroidea of Portuguese East Africa, collected by Jas. J. Simpson. Proc. R. Soc. Edinb. 18: 45-60

Sivickis, P. B., Domantay, J. S. (1928). The morphology of a holothurian, Stichopus chloronotus Brandt. Philip. J. Sci. 37: 299-332

Sloan, N. A. (1979). A pycnogonid-ophiuroid association. Mar. Biol. 52: 171-176

Sloan, N. A., Clark, A. M., Taylor, J. D. (1979). The echinoderms of Aldabra and their habitats. Bull. Br. Mus. nat. Hist. (Zool.) 37(2): 81-128

Smith, C. L. (1964). Some pearlfishes from Guam, with notes on their ecology. Pacif. Sci 18: 34-40

Smith, C. L., Tyler, J. C. (1969). Observations on the commensal relationship of the western Atlantic pearlfish Carapus bermudensis, and holothurians. Copeia 1969: 206-208

Smith, C. L., Tyler, J. C., Feinberg. M. N. (1981). Population ecology and biology of the pearlfish (Carapus bermudensis) in the lagoon at Bimini, Bahamas. Bull. mar. Sci. 31 :
876-902

Speel, J. A., Dearborn, J. H (1983). Comatulid crinoids from R/ $\mathrm{V}$ Eltamin cruises in the Southern Ocean. Biol. Antarct. Seas 38: 1-60

Stephensen, K. (1933). Some new copepods, parasites of ophiuroids and echinids. Vidensk. Meddr dansk naturh. Foren. 93: 197-213

Stephensen, K. (1935a). Two crustaceans (a cirriped and a copepod) endoparasitic in ophiuroids. Danish IngolfExped. 3(12): 1-18

Stephensen, K. (1935b). Some endoparasitic copepods found in echinids. Vidensk. Meddr dansk naturh. Foren. 98: $223-228$

Stephensen, K. (1940). Parasitic and semiparasitic Copepoda. Zool. Iceland 3(34): 1-24

Stock, J. H. (1959). Copepoda associated with Neapolitan invertebrates. Pubbl. Staz. zool. Napoli 31: 59-75

Stock, J. H. (1966). Copepoda associated with invertebrates from the Guif of Aquaba. 2. Enterognathus lateripes n. sp., a new endoparasite of Crinoidea (Cyclopoida, Ascidicolidae). Proc. K. ned. Akad. Wet (C)69: 211-216

Stock, J. H. (1968a). The Calvocheridae, a family of copepods inducing galls in sea-urchin spines. Bijdr. Dierk. 38: 84-90

Stock, J. H. (1968b). Copepods endoparasitic of tropical holothurians. Bull. zool. Mus. Univ. Ansterdam 1. 89-105

Stock, J. H. (1968c). Dichelima seticauda n. sp., a new copepod parasite of an indonesian abyssal echinid. Crustaceana 1 (Suppl.): 210-214

Stock, J. H. (1971). Collocherides astroboae n. gen., n. sp. a siphonostome cyclopoid copepod living in the stomach of basket stars. Bijdr. Dierk. 41: 19-22

Stock, J. H. (1979). Anoplodactylus ophiurophilus n. sp., a sea spider associated with brittle stars in the Seychelles. Bijdr. Dierk. 48: 156-160

Stock, J. H. (1981). Pycnosomia asterophila, a sea spider associated with the starfish Calliaster from the Philippines. Rés. Camp. MusOrstom Philippines 1 (Mém. Orstom $n^{\circ}$ 91): $309-312$

Stock, J. H., Kleeton, G. (1963). Copépodes associés aux invertébrés des côtes du Roussillon. Vie Milieu 13: $681-702$

Strachan, A. R. (1970). A white sea urchin-acorn barnacle enigma. Calif. Fish Game 56: 134-135

Strasburg, D. W (1961). Larval carapid fishes from Hawaii, with remarks on the ecology of adults. Copeia 1961. $478-480$

Stummer-Traunfels, R. R. von (1903). Beiträge zur Anatomie und Histologie des Myzostoma. I. Myzostoma asteriae Marenz. Z. wiss. Zool. 75: 495-595

Stummer-Traunfels, R. R. von (1926). Myzostomida. In: Kükenthal, W. (ed.) Handbuch der Zoologie, 3(1), p. $132-210$

Suzuki, K., Takeda, M. (1974). On a parthenopid crab, Zebrida adamsii on the sea urchins from Suruga Bay, with a special reference to their parasitic relations. Bull. natn. Sci. Mus. Tokyo 17: 287-296

Tanaka, S. (1908). Description of eight new species of fishes from Japan. Annotnes zool. jap 7: 27-46

Tao, L. (1930). Notes on the ecology and the physiology of Caudina chilensis (Müller) in Mutsu Bay. Proc. 4th Pacif. Sci. Congr., Java 1929, p. 7-11

Telford, M. (1978). Distribution of two species of Dissodactylus (Brachyura: Pinnotheridae) among their echinoid host populations in Barbados. Bull. mar. Sci. 28: 651-658

Telford, M. (1982). Echinoderm spine structure, feeding and host relationships of four species of Dissodactylus (Brachyura: Pinnotheridae). Bull. mar. Sci. 32: 584-594 
Thurston, M. H., Billett, D. S. M., Hassack, E. (1987). An association between Exspina typica Lang (Tanaidacea) and deep-sea holothurians. J. mar. biol. Ass. U.K. 67: $11-15$

Trott, L. B. (1970). Contributions to the biology of Carapid fishes (Paracanthopterygii: Gadiformes). Univ. Calif Publs Zool. 89: 1-41

Trott, L. B. (1981). A genera! review of the pearlfishes (Pisces, Carapidae). Bull. mar Sci. 31 623-629

Trott, L. B., Garth, J. S. (1970). Lissocarcinus orbicularis Dana (Portunidae, Caphyrinae) commensal with Holothuria argus Jaeger. A new host record; cohabition with the pearlfish, Carapus homei (Richardson). Crustaceana 19: 320-321

Trott, L. B., Trott, E. B. (1972). Pearlfishes (Carapidae Gadiformes) collected from Puerto Galera, Mindoro, Philippines. Copeia 1972: 839-843

Ummerkutty, A. N. (1970). Description of Sabelliphilus foliacea sp. n. (Copepoda, Cyclopoidea) with notes on the affinities of the species. Rec. zool. Survey India 64 101-105

Vader, W. (1978). Association between amphipods and echinoderms. Astarte 11·123-134

Van der Land, J. (1975). The parasitic marine tardigrade Tetrakentron synaptae. Memorie Ist. ital. Idrobiol. 32 (Suppl.): 413-423

Van Meter, V B., Ache, B. W. (1974). Host location by the pearlfish, Carapus bermudensis. Mar Biol. 26: 379-383

Verrill, A. E. (1867). Remarkable instances of crustacean parasitism. Am. J. Sci. 44: 126

Viets, K. (1939). Eine merkwürdige, neue in Tiefsee-Echiniden schmarotzende Halacaridengattung und -art (Acari). Z. Parasitkde 10: 211-216

Voigt, W. (1892). Synapticola teres n. g., n. sp., ein parasitischer Copepode aus Synapta keferteinii Sel. Z. wiss. Zool. 5 (Suppl.): 31-42

Wagin, V L. (1946). Ascothorax ophioctenis and the position of Ascothoracida Wagin in the system of the Entomostracea. Acta zool. Stockh. 27: 155-267

Wagin, V L. (1950). On new parasitic crustaceans of the family Dendrogasteridae (order Ascothoracida). Trudy Leningr O-va. Estestvoispyt. 70(4): 3-98. (Russian)
Wagin, V L. (1957). Dendrogasteridae (Entomostraca Ascothoracida) aus den Asteroidea der Beringsee. Trudy Leningr O-va. Estestvoispyt. 73(4): 58-63. (Russian; German summary)

Wagin, V L. (1964). On Parascothorax sinagodoides gen. n. sp. n. parasitizing an Ophiura quadrispina Clark and some remarks on geographical distibution of Ascothoracidae. Trudy Inst. Okeanol. 69: 271-284. (Russian; English summary)

Wagin, V L. (1968). Ascothorax gigas sp. nov. from the Antarctic ophiuroid Ophionotus victoriae and data on the distribution of the genus Ascothorax. Sbornik Kratkikh Soobshchenii Zoologia 2: 10-19. (Russian)

Wagin, V L. (1976). Ascothoracida. Kazan Univ. Press, Kazan. (Russian)

Warén, A. (1981). Ctenosculum hawaiiense Heath, an ascothoracican (Cirripedia) described as a mollusc. Crustaceana 40: 310-312

West, B., West, L. (1976). A note on the uptake of dissolved nutrients from sea water by the endoparasitic myzostome Pulvinomyzostomum pulvinar, in situ in its host Leptometra phalangium. Vie Milieu 26: 47-52

Wheeler, W. M. (1896). The sexual phases of Myzostoma. Mitt zool. Stn Neapel 12: 227-302

Wheeler, W M. (1904). A new Myzostoma, parasitic in a starfish. Biol. Bull. mar biol. Lab., Woods Hole 8: 75-80

Winterbourn, M. J., Anderson, N. H. (1980). The life history of Philanisus plebeius Walker (Trichoptera: Chathamiidae), a caddisfly whose eggs were found in a starfish. Ecol. Entomol. 5: 293-303

Yosii, N. (1928a). Note on a Carapus in a starfish. Annotnes zool. jap. 2: 339-340

Yosii, N. (1928b). Note on Myriocladus. J. Fac. Sci. imp. Univ. Tokyo (4)2: $337-347$

Zankert, A. (1940). Studien über das Verhalten von Fierasfer acus Brünn. beim Aufsuchen und Beziehen seines Wohntieres Holothuria tubulosa Gm. SBer. Ges. naturf. Fr 1940 $95-104$ 